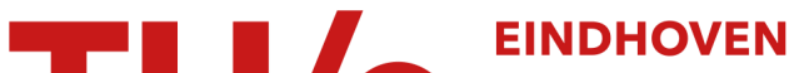 UNIVERSITY OF TECHNOLOGY
}

\section{Early age mechanical behaviour of 3D printed concrete}

\section{Citation for published version (APA):}

Wolfs, R. J. M., Bos, F. P., \& Salet, T. A. M. (2018). Early age mechanical behaviour of 3D printed concrete: Numerical modelling and experimental testing. Cement and Concrete Research, 106(April 2018), 103-116. https://doi.org/10.1016/j.cemconres.2018.02.001

\section{Document license:}

TAVERNE

DOI:

10.1016/j.cemconres.2018.02.001

Document status and date:

Published: 09/02/2018

\section{Document Version:}

Publisher's PDF, also known as Version of Record (includes final page, issue and volume numbers)

\section{Please check the document version of this publication:}

- A submitted manuscript is the version of the article upon submission and before peer-review. There can be important differences between the submitted version and the official published version of record. People interested in the research are advised to contact the author for the final version of the publication, or visit the $\mathrm{DOI}$ to the publisher's website.

- The final author version and the galley proof are versions of the publication after peer review.

- The final published version features the final layout of the paper including the volume, issue and page numbers.

Link to publication

\section{General rights}

Copyright and moral rights for the publications made accessible in the public portal are retained by the authors and/or other copyright owners and it is a condition of accessing publications that users recognise and abide by the legal requirements associated with these rights.

- Users may download and print one copy of any publication from the public portal for the purpose of private study or research.

- You may not further distribute the material or use it for any profit-making activity or commercial gain

- You may freely distribute the URL identifying the publication in the public portal.

If the publication is distributed under the terms of Article 25fa of the Dutch Copyright Act, indicated by the "Taverne" license above, please follow below link for the End User Agreement:

www.tue.nl/taverne

Take down policy

If you believe that this document breaches copyright please contact us at:

openaccess@tue.nl

providing details and we will investigate your claim. 


\title{
Early age mechanical behaviour of 3D printed concrete: Numerical modelling and experimental testing
}

\author{
R.J.M. Wolfs*, F.P. Bos, T.A.M. Salet \\ Department of the Built Environment, Eindhoven University of Technology, Eindhoven, The Netherlands
}

\section{A R T I C L E I N F O}

\section{Keywords:}

3D printing

Fresh concrete

Mechanical properties

Finite element modelling

Experimental validation

\begin{abstract}
A B S T R A C T
A numerical model was developed to analyse the mechanical behaviour of fresh, 3D printed concrete, in the range of 0 to $90 \mathrm{~min}$ after material deposition. The model was based on a time-dependent Mohr-Coulomb failure criterion and linear stress-strain behaviour up to failure. An experimental program, consisting of unconfined uniaxial compression tests and direct shear tests, was set-up and performed to obtain the required material properties. The material tests showed that the Young's modulus and cohesion linearly increase with fresh concrete age, as do the compressive and shear strength. The Poisson's ratio and angle of internal friction, on the other hand, remain constant. Subsequently, the model was validated by comparison to printing experiments. Modelling of the printed samples reproduced the experimental results qualitatively, but the quantitative agreement with the print experiments could be improved. However, the deviations can well be explained and the type of failure-deformation mode was predicted accurately.
\end{abstract}

\section{Introduction}

For some decades now, the construction industry has gradually moved towards a digitalization of processes. In the design phase, architects work in a digital environment, and engineers have adopted numerical tools for structural analyses. Data exchange using Building Information Models (BIM), which allow automated design evaluation, has become standard in many practices. Consequently, automation in the construction phase is becoming more common, as illustrated by e.g. advanced prefab and precast industries. More recently, explorations have started into new, additive manufacturing techniques for the construction industry. Many construction materials can be used with various 3D printing methods to manufacture objects ranging in scale from connection elements, to components, to complete buildings. Although 3D print techniques for e.g. ceramics, steel, polymers, foams, glass, or concrete are still in different stages of Technology Readiness Level, their potential in terms of design optimization and customization is becoming increasingly clear [1-5].

3D Concrete printing is one of the areas which is rapidly developing, as illustrated by the high frequency in which new projects are being presented by a growing number of private enterprises and research institutes worldwide [6-9]. These projects still have a case study character: they showcase the possibilities of what could be printed. However, a fundamental understanding of the particularities of the print process and its relation to the properties of the printed product has yet to be developed.
An obvious path of research for 3D concrete printing focuses on the final, hardened printed product, including the interface strength between layers, which is expected to deteriorate for larger interval times between layers [10]. Le et al. [11] discuss a reduction in bond strength between layers as the printing time gap increases, whereas Duballet et al. [12] report a toolpath dependent failure mode in printed specimens.

However, there is an additional, new phase that needs to be addressed: the mechanical behaviour during the 3D printing process. While printing, layers of concrete are deposited on top of each other without the presence of formwork to confine and stabilize the material. The fresh concrete should therefore be sufficiently strong, stiff, and stable to carry its self-weight and the weight of the layers above it, and limit deformations.

First experiences with 3D concrete printing by the authors $[5,13]$ and other research institutes $[14,15]$ have shown that both the printability (i.e. the structural integrity of the object during printing) and the post-print properties (e.g. interface strength) are highly dependent on print process parameters, such as time, temperature, kinematics etc. This has resulted in premature object failures during printing as well as variations in quality of the printed product.

The process-product dependency is also known from 3D printing processes used in other industries. For instance, Dunbar et al. [16] identify a number of build failures that can occur in laser powder bed fusion (LPBF) due to residual thermal stresses, including layer

\footnotetext{
* Corresponding author.

E-mail address: r.j.m.wolfs@tue.nl (R.J.M. Wolfs).
} 
delamination, post-build distortions, and more. To be able to accurately predict print product quality (during and after printing) and avoid failures (in other words: obtain a robust print process), extensive finite element-based methods have been developed to model the printing process, including transient behaviour such as time dependencies.

For 3D concrete printing, however, such a virtual production tool has hitherto been non-existent. For low-cost/crude-quality applications, the necessity of such a tool could be debated. But when aiming to compete with existing high-quality manufacturing methods generally associated with prefabricated concrete, it is indispensable. Therefore, this study presents an experimentally validated modelling method of the 3D concrete printing process to assess the printability, based on perhaps the primary process-product dependency: the time-dependent development of mechanical properties of fresh concrete during printing.

Experimental results $[17,18]$ and an analytical framework on fresh printed concrete [19] provide a starting point. However, these concern a purely strength-based failure criterion, whereas in-print failures are also often initiated by loss of stability, as observed in a range of (largely unpublished) printing experiments. Besides, layers may not be stacked exactly on top of each other, either on purpose (cantilevering objects), or due to imperfections/vibrations in the printing process. The printing process itself is not necessarily a constant one, as stops may occur or the printing strategy may change from layer to layer. Additionally, concerning multi material printing or filling the printed structure with a secondary material while printing, stresses may occur not exclusively in vertical direction. In these cases the critical layer is no longer the one with the highest loading, i.e. the initial layer, and an analytical strength-based criterion no longer holds. Any approach should thus be based on the development of both the mechanical properties (including stiffness), and the 3D geometry of the printed object over time.

Developing and validating a modelling method for 3D concrete printing presents four major challenges. First, a suitable material failure model has to be selected. Conventional experiments and analyses on fresh concrete generally focus on concrete in a dynamic state, in relation to e.g. pumpability or filling of formworks. These theories do not hold for fresh 3D printed concrete, which is in a static state after extrusion. Therefore a model was adopted for the state of the material directly after printing, i.e. in between a Bingham fluid and a proper solid. Secondly, specific experimental methods, based on geotechnical test methods of soils, had to be devised to determine the relevant material properties. Once the tests had been carried out, a FE-model was developed as a third step, using the commercially available Abaqus FEcode. It was used to model the material tests and evaluate the results, which proved to be in very close agreement with the experimental results. Finally, a 3D concrete print was modelled with the developed method and validated by comparing the results to actual prints of the same design. This involved development of custom optical measuring methods to track the object behaviour during printing and allow for comparison to the FE-results. Although the quantitative agreement could be improved, the qualitative similarity between the experimental and numerical results already is striking.

\section{Modelling parameters for $3 \mathrm{D}$ printed concrete}

3D concrete printing generally requires a low- to zero-slump material to maintain shape and position after deposition. In this research, a custom designed printable concrete mix was applied as described by [5], containing Portland cement (CEM I 52.5 R), siliceous aggregate with a maximum particle size of $1 \mathrm{~mm}$, limestone filler, additives, rheology modifiers and a small amount of polypropylene (PP) fibers. Fig. 1 shows a close up of the concrete during printing.

The shape stability is also an essential property for other concrete construction processes in which the material is loaded in the dormant period, like slip forming [20,21]. The 'green strength' which allows fresh concrete to carry its own weight immediately after mixing or

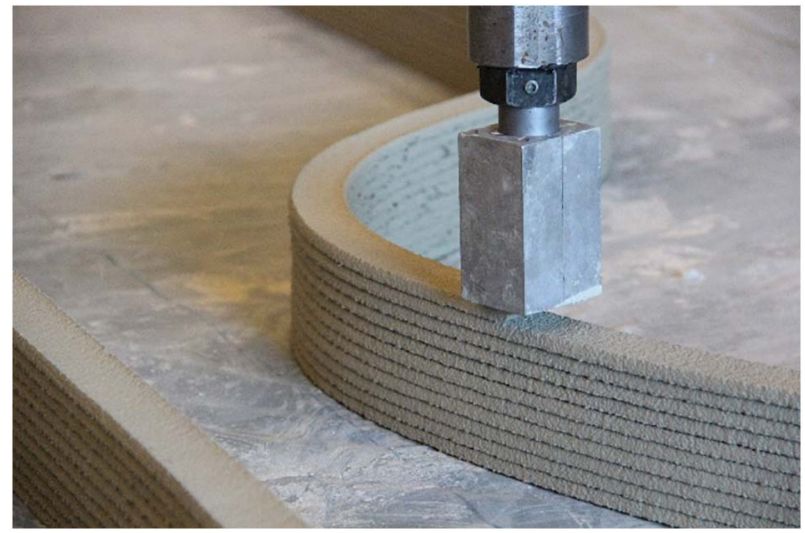

Fig. 1. Close-up of concrete filament during printing: a low- to zero-slump material is required to maintain shape and position after deposition.

compacting, is attributed to a combined inter particle friction, and cohesion [22]. This mechanical behaviour is similar to that of soils, and as such a Mohr-Coulomb yield criterion is proposed by [23-26], and likewise adopted in the present study, albeit in an expanded form to include time dependent development of the material properties, as given in Eq. 1:

$\tau_{y}=C(t)+\sigma_{n} \cdot \tan (\varphi(t))$

where $C$ is the cohesion between particles bonded by cement, and $\varphi$ is the angle of internal friction caused by the frictional resistance and interlocking between internal particles, both of which may be time dependent. The shear yield stress and acting normal stress are given by $\tau_{y}$ and $\sigma_{n}$, respectively.

Two competing time dependent processes during printing determine structural failure of a printed object: the increasing strength and stiffness caused by thixotropic build-up of the concrete $[27,28]$ needs to keep up with the gradually increasing load as more layers are deposited on each other. The latter effect can be incorporated in the numerical model by stepwise load increments, whereas the former is accounted for by updating the yield criterion over time. Experimental findings presented by [29-31] have shown the thixotropic build-up causes the Mohr-Coulomb parameters to evolve significantly within the time frame of a typical printing process. Consequently, the parameters $C(t)$ and $\varphi(t)$ have been established experimentally in this study through direct shear tests on specimens of different age.

However, since print object failures are often stability-driven, the stress-strain relation before failure also was established to determine the stiffness, taken as the tangent Young's modulus $E(t)$, and Poisson ratio $\nu(t)$. These parameters are both needed to model the object response before yielding. As the direct shear test is unsuitable to obtain these due to the non-uniform stress distribution in the sample, an unconfined compression test was adopted. Both experiments are discussed in the next section.

A print object is considered failed when the yield stress is reached at any point in the object, as it will likely coincide with extensive deformations, progressive collapse, and cracking. Therefore, complex post-yield phenomena like viscous behaviour and dilatancy effects have not been established experimentally. Rather, a dilatancy angle $\psi$ has been assumed merely in order to avoid abortion of the numerical analysis when the yield stress is (locally) exceeded, as discussed further in Section 3.3.3.

\section{Experimental program}

An experimental program is designed to define the Mohr-Coulomb parameters, and strength and stiffness development of fresh 3D printed concrete. Similar to $[17,29,32,33]$ the authors adopted geotechnical 
Table 1

Summary of experimental program, where the number of samples indicates the amount of tests for each variable.

\begin{tabular}{lll}
\hline & $\begin{array}{l}\text { Unconfined uniaxial } \\
\text { compression test (UUCT) }\end{array}$ & $\begin{array}{l}\text { Direct shear test } \\
\text { (DST) }\end{array}$ \\
\hline Age [min] & $0,15,30,60,90$ & $0,15,30,60,90$ \\
Normal load [N] & - & $1.5,11.5,21.5$ \\
$\begin{array}{l}\text { Number of samples per set } \\
\text { Total number of samples }\end{array}$ & 6 & 5 \\
\hline
\end{tabular}

(soil) tests to apply for concrete in the dormant phase.

Contrary to tests on soil, it is essential that the tests on fresh concrete can be executed swiftly to eliminate the influence of thixotropic build-up within a single test and to be able to attribute the properties to a specific age. Additionally, the tests should be easily repeatable to assess the properties at different material ages. The preparation and testing procedures should be such that unintentional breakdown of the thixotropic build-up is minimized.

The unconfined uniaxial compression test and direct shear test fulfil these requirements and can be used to define the Mohr-Coulomb strength and stiffness parameters. Both tests have been performed at multiple fresh concrete ages of $t=0,15,30,60$ and $90 \mathrm{~min}$. Here $t=0$ is the earliest time possible taking into account compaction, demolding, placing of the specimens in the test setup and starting the test, which takes approximately $5 \mathrm{~min}$. The time range of 0 to $90 \mathrm{~min}$ corresponds to the typical duration of a 3D printing process, and is well within the dormant period of the material, as the initial setting time is defined at approximately $2 \mathrm{~h}$ by standard Vicat measurements [34]. The experimental program is summarized in Table 1 . In total, 30 compression tests

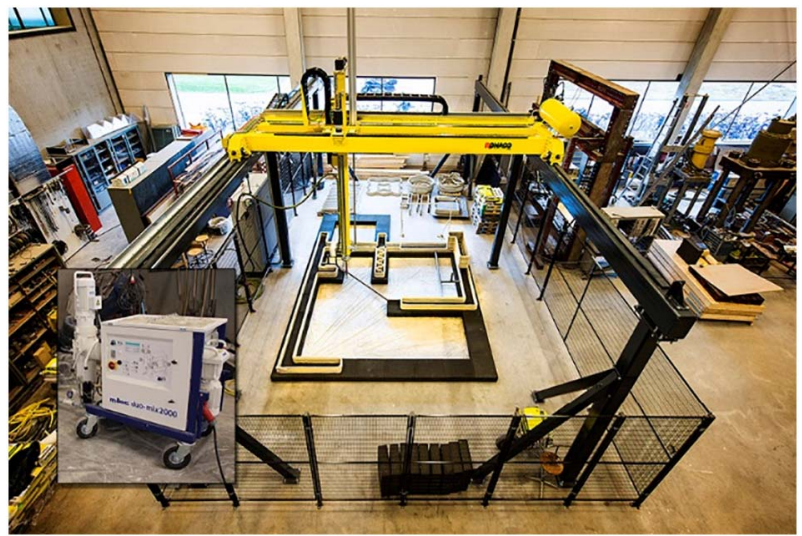

Fig. 2. 3DCP Setup, consisting of 4 axis gantry robot, numerical control unit, and concrete mixer and pump. and 75 shear tests have been performed.

The fresh concrete is extracted after mixing and pumping using the 3DCP 3D printer setup [5], which consists of an M-Tec Duomix 2000 mixer-pump with a linear displacement pump that feeds concrete through a $\emptyset 1$ inch, $10 \mathrm{~m}$ length hose (Fig. 2). Consistent mixing speed and pumping frequency are maintained for every test. All samples were prepared and tested at room temperature $T=22^{\circ} \mathrm{C}$. The sample temperature at loading was slightly elevated to an average of $T=24^{\circ} \mathrm{C}$, which is attributed to the accumulated heat in the mixer-pump.

\subsection{Uniaxial unconfined compression test}

Uniaxial unconfined compression tests (UUCT) were performed on cylindrical samples. The specimen dimensions were designed according to the ASTM D2166 [35]. The cylinder diameter of $d=70 \mathrm{~mm}$ is large enough to eliminate size effects due to particle size and distribution, while the height is $h=140 \mathrm{~mm}$, so that $h / d=2$ to allow a diagonal shear failure plane to form. The material was extracted into steel cylindrical molds lined with a thin sheet of Teflon and compacted three times for $10 \mathrm{~s}$ on a $30 \mathrm{~Hz}$ vibration table to realize a homogeneous sample. Just before testing the sample was carefully demolded and the Teflon sheet removed.

The specimens were loaded in an INSTRON test rig equipped with a $5 \mathrm{kN}$ load cell, see Fig. 3. The load is transferred into the sample through a steel plate with the same diameter. A double sheet of Teflon is placed on both sides of the sample, to realize free support conditions. From soil tests it is known that the rate of loading influences the strength and deformation characteristics, and should be chosen in relation to the material's application. Thus, the displacement controlled tests have been performed at a rate of $30 \mathrm{~mm} / \mathrm{min}$, chosen to mimic the loading rate during printing and allow the test to be performed fast enough to neglect effects of thixotropic build-up. The average test time up to $25 \%$ strain was equal to $1.2 \mathrm{~min}$. In total 6 specimens were tested for each fresh concrete age, resulting in a total of 30 specimens (Table 1).

The machine load and displacement were recorded. In addition, the vertical and lateral deformation of the specimen was measured. Due to the low stiffness of the fresh material and the occurring large deformations, it appeared not possible to apply a physical measurement device without severely affecting the specimen. Non-contacting, optic measurement systems were used instead. Local deformations were measured at mid height of the sample, by means of two white dots in both vertical and lateral direction, as shown in Fig. 3. These dots were tracked and recorded by the optic measurement system. However, in some of the tests, a local shear plane formed in between the measurement dots, which rendered the deformation measurements unrepresentative for the behaviour of the specimen Thus, additionally the global deformation was measured by taking high resolution (18 MP) photographs during the test, and post processing this output in National
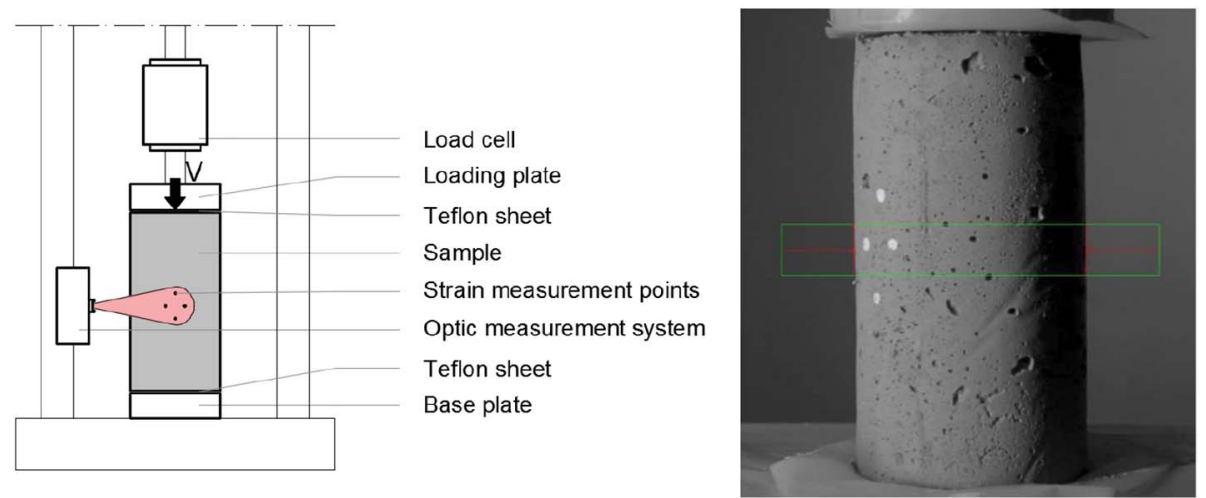

Fig. 3. Schematic of uniaxial unconfined compression test (left) and photograph of a sample (right). The white dots are used as strain measurement points. 


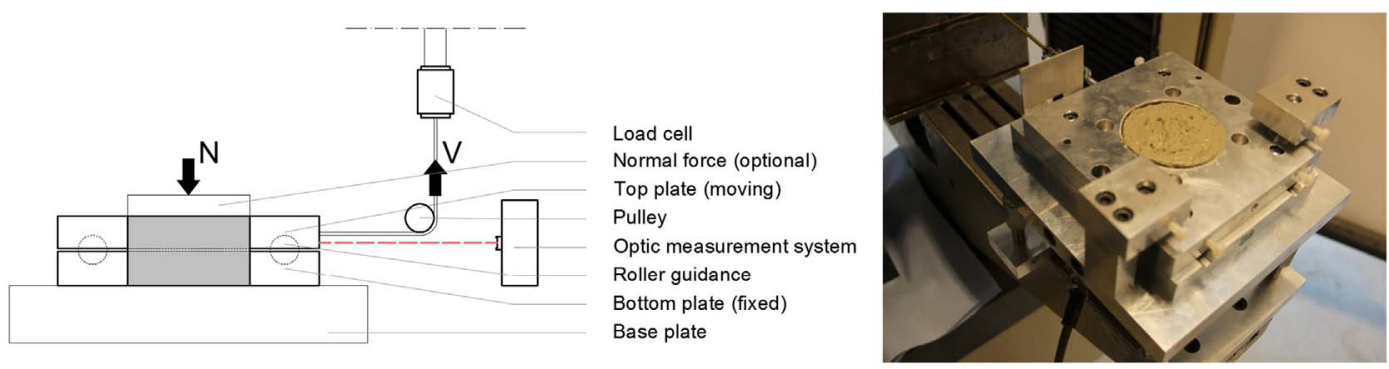

Fig. 4. Schematic of direct shear test (left) and photograph of the setup without a normal load applied (right).

Instruments Vision Builder software. Results of both systems were compared and deemed similar and accurate.

\subsection{Direct shear test}

Direct shear tests (DST) were performed on cylindrical samples. The specimen dimensions were designed according to ASTM D3080 [36]. Two horizontal plates with a circular opening with diameter $d=70 \mathrm{~mm}$ were positioned on top of each other, such that the total specimen height $h=40 \mathrm{~mm}$. The plates were filled in three steps with fresh concrete and compacted for $10 \mathrm{~s}$ on a $30 \mathrm{~Hz}$ vibration table to realize a homogeneous sample.

The specimens were loaded in a Schenck RM100 test rig equipped with a $100 \mathrm{kN}$ load cell. A steel cable translated the vertical displacement of the load cell via a pulley to the top plate, depicted in Fig. 4. This resulted in a constant horizontal displacement rate of $15 \mathrm{~mm} / \mathrm{min}$, imposed on the top plate. Additionally, steel weights were used to apply external normal loads as a test variable to the top surface of the specimens. Three load values were applied: $0 \mathrm{~N}$ (no weight), $10 \mathrm{~N}$ and $20 \mathrm{~N}$, so that the two unknowns $C(t)$ and $\varphi(t)$ could be established. Together with the self-weight of the top half of concrete specimen, this resulted in normal loads of $1.5 \mathrm{~N}, 11.5 \mathrm{~N}$, and $21.5 \mathrm{~N}$, respectively, on the shear plane, which is well defined in the middle of the specimen. The average test time was equal to $1.2 \mathrm{~min}$, which is considered as fast enough to neglect effects of thixotropic build-up during a single test. In total 5 specimens were tested for each age and normal load combination, resulting in a total of 75 specimens (Table 1).

To minimize the friction between the two halves of the shear box, a well-known issue reported e.g. by $[37,38]$, two grooves were machinemilled in the top and bottom part of the plates. Four steel balls were placed in these grooves as rollers. Calibration of the test setup showed the friction in the shear box was thus reduced to $6 \%$ of the average failure load of the weakest (i.e. $t=0$ ) samples, as approximately $0.8 \mathrm{~N}$ was required to move the top plate over the bottom one.

\subsection{Results and discussions}

\subsubsection{Compression tests}

Compression tests were performed up to $50 \%$ vertical strain, i.e. $70 \mathrm{~mm}$ displacement. Load-displacement results are shown in Fig. 6. Note that one result from both $t=0$ and $t=15 \mathrm{~min}$ was excluded from further discussions as these test were improperly recorded due to issues with the measurement device.

From Fig. 6 it is clearly observed that the mechanical behaviour of fresh concrete changes in the early age of 0 to $90 \mathrm{~min}$. The peak force increases for older specimens, and the post initial-path behaviour varies with specimen age. For every sample, the load initially increases approximately linearly as the vertical displacement increases. After this initial path, the increment of loading decreases as deformations grow. The younger specimens (i.e. $t=0,15$, and $30 \mathrm{~min}$ ) show an increment in load with increasing deformations, up to a certain plateau. The older specimens (i.e. $t=60$ and $90 \mathrm{~min}$ ), on the other hand, show a load decrease after the initial peak, again to a certain limit. This difference in behaviour is attributed to the occurring lateral deformations and failure behaviour. Due to the relatively low stiffness, the early age specimens significantly expand in lateral direction as the vertical deformation increases. A distinct failure plane is not formed and the specimens fail by 'barreling' (bulging), see Fig. 5. As a result, the cross section grows under vertical displacement, leading to an increase of force. The older specimens however, expand much less in lateral direction and have a more distinct failure plane formation (Fig. 5), which roughly coincides with the peak force, after which the loading decreases. This is a wellknown phenomenon in soils, where the failure modes of barreling or by shear plane are closely related to the ductility and brittleness of the material [39-41].

The load-displacement data for each specimen was translated into stress-strain diagrams. Due to the large occurring deformations, especially at early ages, all stresses are calculated using an updated cross section. The horizontal displacement measurements from the optic measurement systems are used to update the cross section at every measurement point. The data is cut-off at $25 \%$ strain, as severe deformations and cracks were observed after this point and the measured deformations resulted in unrealistic values. For every specimen age the ultimate strength was achieved well before the cut-off value.

Arguably, a correction for self-weight could be included, in particular for early concrete ages $(t=0 \mathrm{~min})$, for which the total self-weight of the specimen of $10.7 \mathrm{~N}$ corresponds to approximately $23 \%$ of the average failure load. At older ages $(t=90 \mathrm{~min})$, this percentage reduces to $11 \%$. However, the failure plane usually does not occur at the bottom edge of the sample, but in the center region of the cylinder. Thus, the full self-weight should not be included in the strength calculation. As the failure plane does not always occur at the same specimen height, each test should be corrected for a different self-weight, resulting into difficult comparisons. Moreover, not incorporating the self-weight is a safe approximation of the strength. Thus, the self-weight of each sample will not be added in the strength derivations.
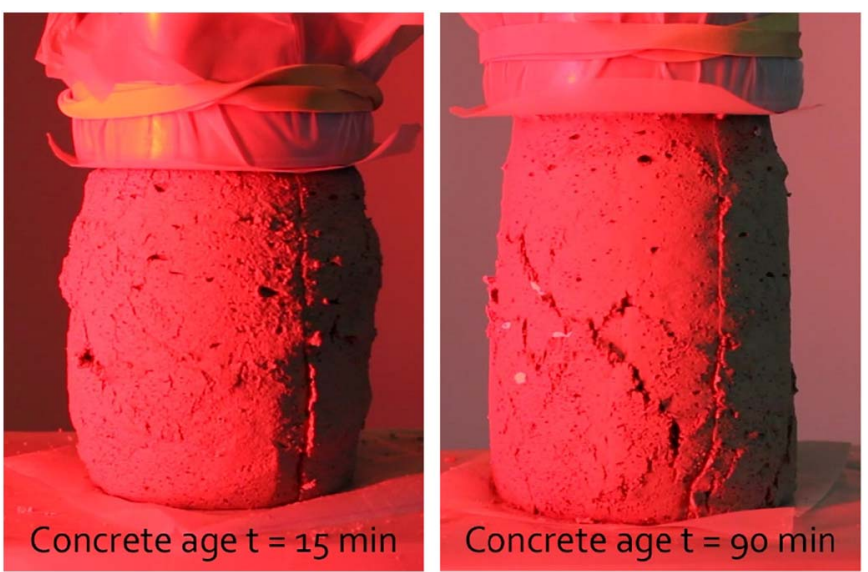

Fig. 5. Typical failure observed in compression tests on fresh concrete. An early age sample of $t=15 \mathrm{~min}$ shows 'barreling' (left), while an old age specimen of $t=90 \mathrm{~min}$ shows a distinct shear failure plane (right). 

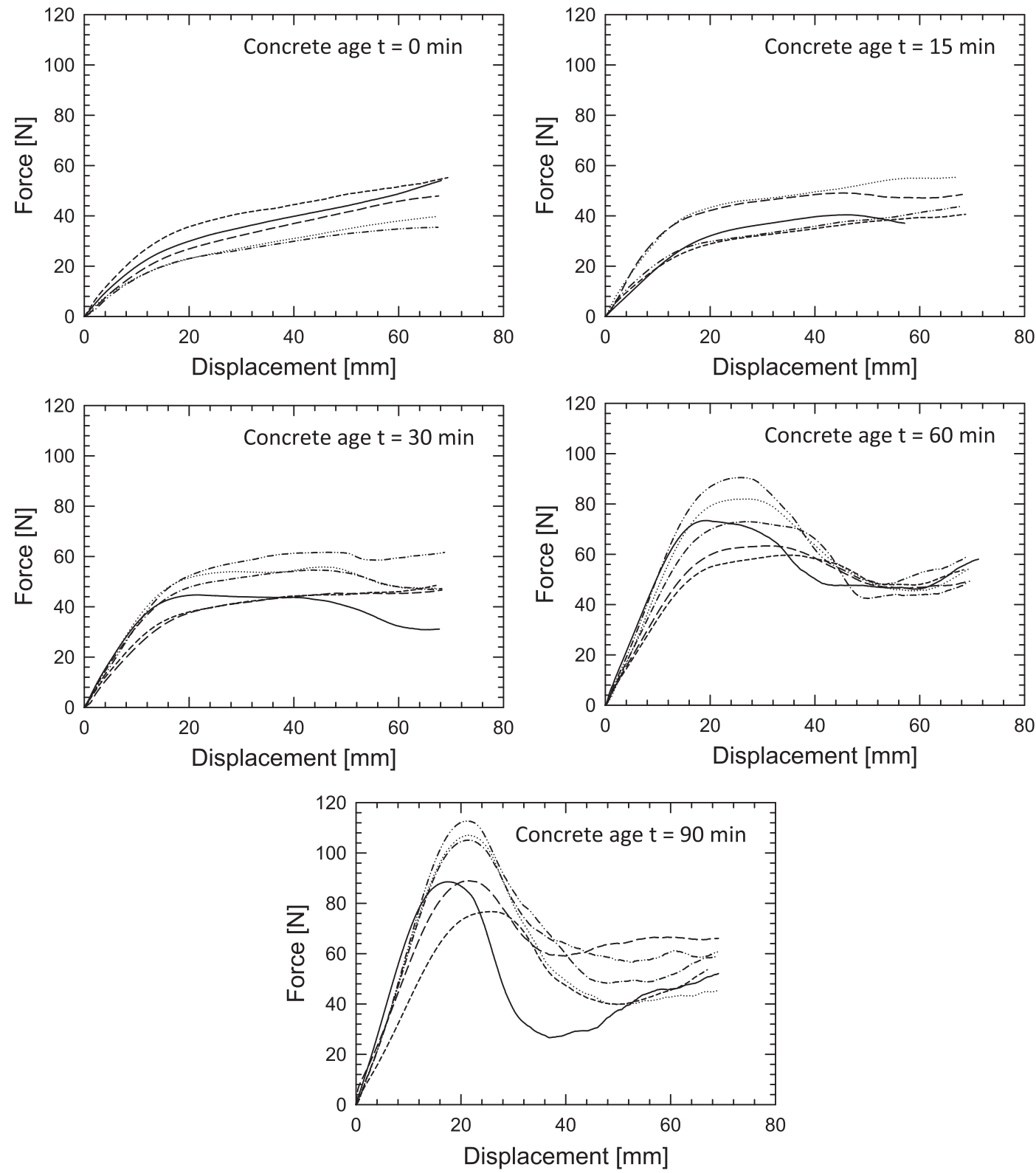

Fig. 6. Force - displacement diagrams of compression tests for concrete age $t=0$ to $90 \mathrm{~min}$.

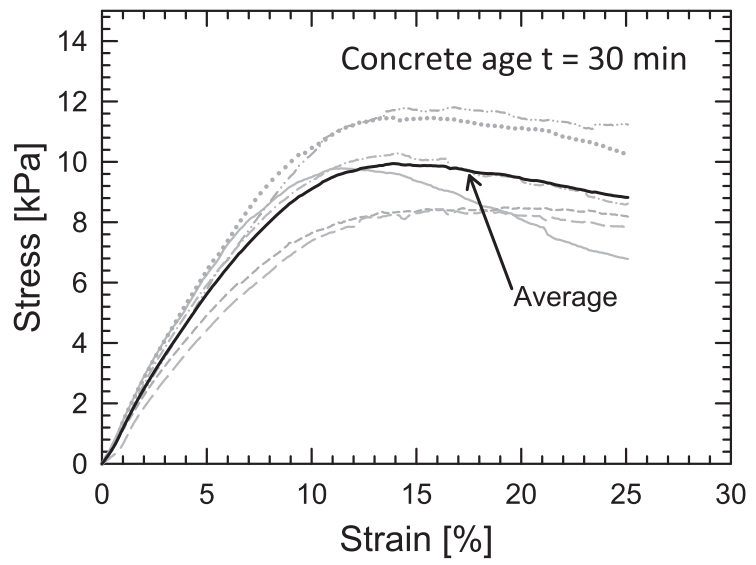

Fig. 7. Stress-strain diagram of compression tests for concrete age $t=30 \mathrm{~min}$. The grey lines indicate the individual tests results, the solid black line represents the average stressstrain relation.

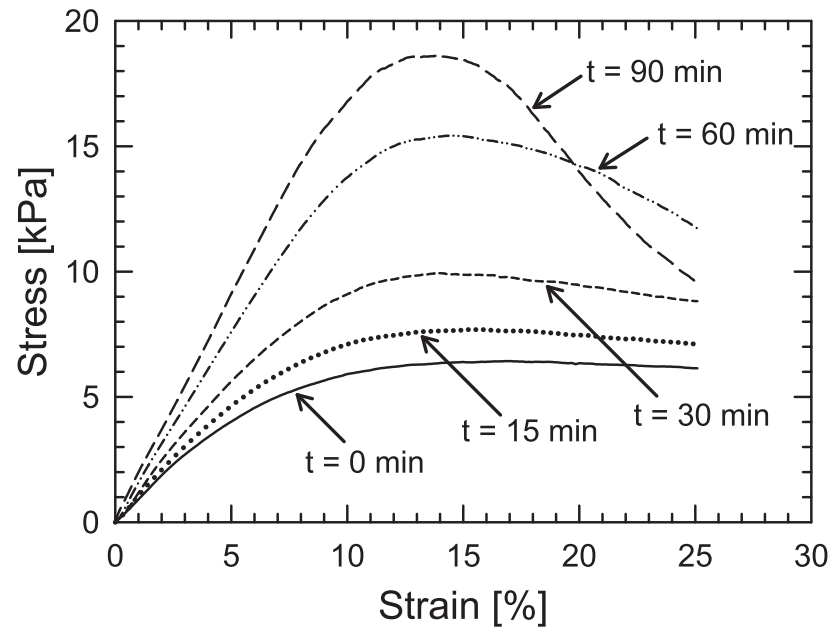

Fig. 8. Average stress-strain relations for each concrete age $t=0$ to $90 \mathrm{~min}$. 
Typical stress-strain data is shown in Fig. 7 for a concrete age of $30 \mathrm{~min}$. Using the 6 experiments for each age, an average stress-strain relation can be determined as indicated by the black solid line. Fig. 8 gives an overview of the average stress-strain relation for each concrete age, clearly showing a significant increase of both strength and stiffness in time. The unconfined compressive strength $\sigma_{\mathrm{y}}$ is defined for each test as the maximum occurring stress after area correction, and is summarized in Table 2 along with each sample's density, and Young's modulus measured at 5\% strain. The $5 \%$ strain limit was within the linear range for each age. Moreover, it provides a practical limit in the printing process, as significant deformations would compromise the geometrical accuracy of the object.

The average compressive strength of the youngest specimens is equal to $6.37 \mathrm{kPa}$, which increases to an average $18.93 \mathrm{kPa}$ at $90 \mathrm{~min}$. These values are in the same order of magnitude as reported by other early age compressive studies on printable concrete [17,18]. A linear fit is found, as depicted in Fig. 9. The average Young's modulus starts at $0.074 \mathrm{MPa}$ and develops linearly to $0.186 \mathrm{MPa}$ (Fig. 9). When normalizing the strength and stiffness value to their maximum average value at $t=90 \mathrm{~min}$, their rates of development can be compared and are deemed similar. This is indicated by the approximately $45^{\circ}$ angle in Fig. 10, which is a linear fit through the normalized average strength and stiffness values. The measured densities are approximately constant and therefore excluded from further discussions.

\subsubsection{Shear tests}

Shear tests were performed up to $35 \mathrm{~mm}$ horizontal displacement. Typical load-displacement results are shown in Fig. 11 for a $1.5 \mathrm{~N}$ normal load (only self-weight). For every sample the load initially increases approximately linearly as the horizontal displacement increases. After this initial path, the increment of loading decreases as deformations grow. This post-initial path behaviour varied with specimen age. Similar to the compression tests, the material shows a more plastic behaviour at early age, which gradually becomes a more brittle

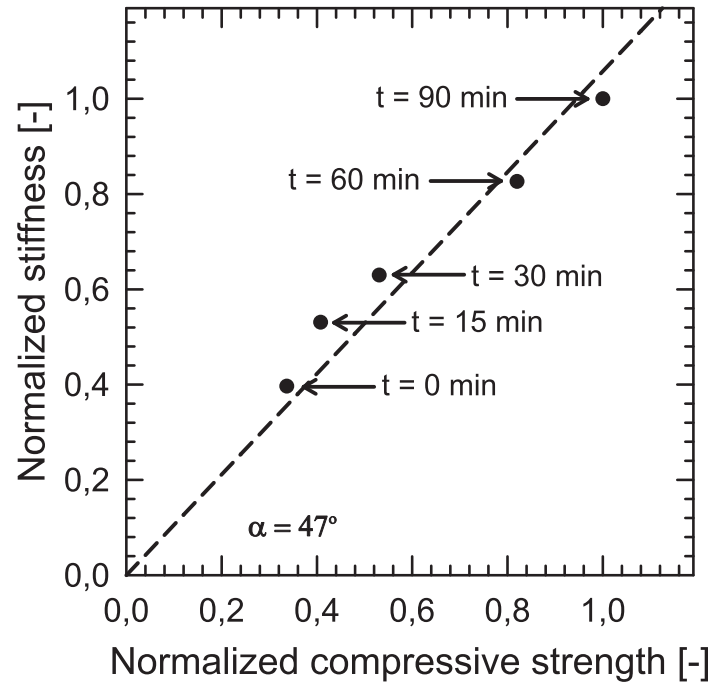

Fig. 10. Comparison between the strength and stiffness development up to $90 \mathrm{~min}$. All values are normalized to their maximum average value at $t=90 \mathrm{~min}$.

failure for older specimens. This is shown by a steady decrease of force after the initial peak for specimens $t=0, t=15$, and $t=30$, while a more distinct drop in force is observed for the older ages of $t=60$ and $t=90$.

The load-displacement data for each specimen is translated into shear stress-shear displacement diagrams. The data is cut-off at $25 \mathrm{~mm}$, as after this deformation the measured data were disturbed by the friction of the top half of concrete sliding over the bottom aluminum plate as observed by the oscillations in the force displacement diagrams. For every specimen age and normal load combination the ultimate strength was achieved well before the cut-off value.

Table 2

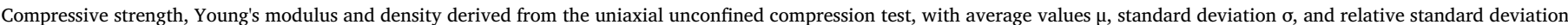
RSD.

\begin{tabular}{|c|c|c|c|c|c|c|c|c|c|}
\hline \multirow[t]{2}{*}{ Concrete age [min] } & \multicolumn{3}{|c|}{ Compressive strength $\sigma_{\mathrm{y}}[\mathrm{kPa}]$} & \multicolumn{3}{|c|}{ Young's modulus E [MPa] } & \multicolumn{3}{|c|}{ Density $\rho\left[\mathrm{kg} / \mathrm{m}^{3}\right]$} \\
\hline & $\mu_{\sigma y}$ & $\sigma_{\sigma y}$ & RSD & $\mu_{\mathrm{E}}$ & $\sigma_{\mathrm{E}}$ & RSD & $\mu_{\rho}$ & $\sigma_{\rho}$ & RSD \\
\hline 0 & 6,37 & 1,07 & $17 \%$ & 0,074 & 0,015 & $21 \%$ & 2039 & 15,0 & $0,7 \%$ \\
\hline 15 & 7,71 & 1,42 & $18 \%$ & 0,099 & 0,022 & $22 \%$ & 2007 & 8,90 & $0,4 \%$ \\
\hline 30 & 10,05 & 1,31 & $13 \%$ & 0,117 & 0,016 & $14 \%$ & 2033 & 9,15 & $0,4 \%$ \\
\hline 60 & 15,52 & 2,29 & $15 \%$ & 0,154 & 0,021 & $14 \%$ & 2030 & 10,6 & $0,5 \%$ \\
\hline 90 & 18,93 & 3,92 & $21 \%$ & 0,186 & 0,036 & $19 \%$ & 1994 & 15,0 & $0,8 \%$ \\
\hline
\end{tabular}
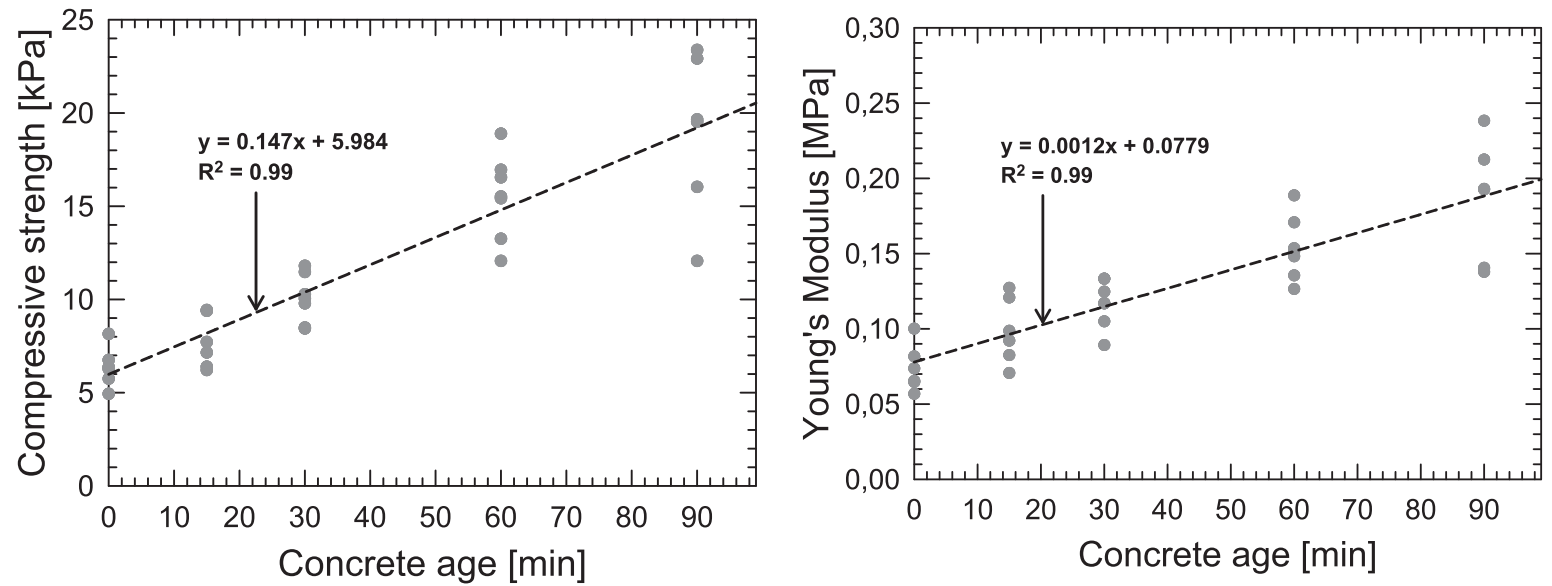

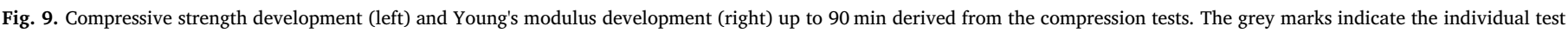
results, the dashed black line represents a linear fit with $\mathrm{R}^{2}=0.99$, based on the average test results. 

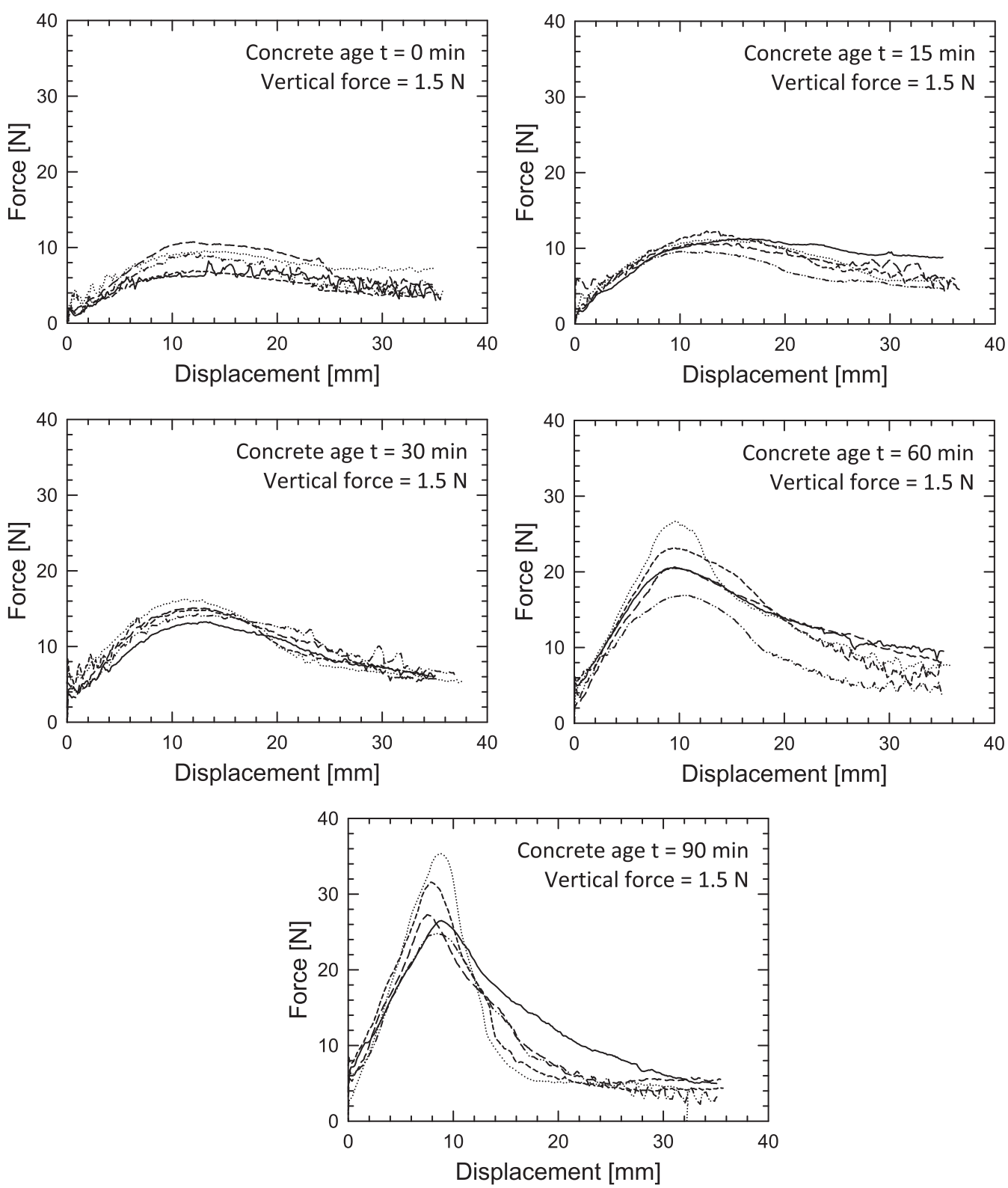

Fig. 11. Force - displacement diagrams of shear tests for concrete age $t=0$ to $90 \mathrm{~min}$ and normal load $1.5 \mathrm{~N}$.

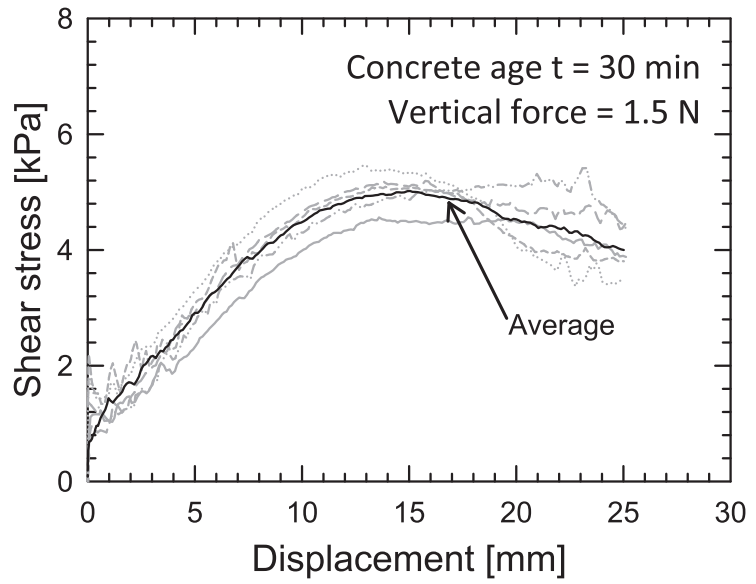

Fig. 12. Shear stress-displacement diagram of direct shear tests for concrete age $t=30 \mathrm{~min}$ and normal load $1.5 \mathrm{~N}$. The grey lines indicate the individual tests results, the solid black line represents the average relation.

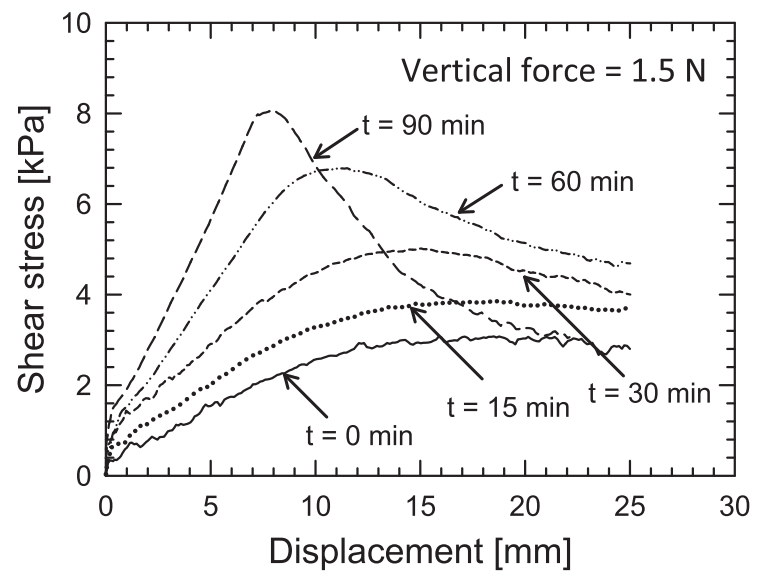

Fig. 13. Average stress-strain relations for each concrete age $t=0$ to $90 \mathrm{~min}$ and normal load $1.5 \mathrm{~N}$. 
Table 3

Shear strength and density derived from the direct shear test, with average values $\mu$, standard deviation $\sigma$, and relative standard deviation RSD.

\begin{tabular}{|c|c|c|c|c|c|c|c|}
\hline \multirow{2}{*}{$\begin{array}{l}\text { Concrete age } \\
\text { [min] }\end{array}$} & \multirow{2}{*}{$\begin{array}{l}\text { Normal } \\
\text { load }[\mathrm{N}]\end{array}$} & \multicolumn{3}{|c|}{ Shear strength $\tau_{\mathrm{y}}[\mathrm{kPa}]$} & \multicolumn{3}{|c|}{ Density $\rho\left[\mathrm{kg} / \mathrm{m}^{3}\right]$} \\
\hline & & $\mu_{\tau y}$ & $\sigma_{\tau y}$ & RSD & $\mu_{\rho}$ & $\sigma_{\rho}$ & RSD \\
\hline 0 & 1.5 & 3,11 & 0,48 & $15 \%$ & 2033 & 40,0 & $2,0 \%$ \\
\hline 15 & 1.5 & 3,95 & 0,37 & $9 \%$ & 2076 & 30,1 & $1,5 \%$ \\
\hline 30 & 1.5 & 5,08 & 0,30 & $6 \%$ & 2064 & 41,6 & $2,0 \%$ \\
\hline 60 & 1.5 & 6,87 & 0,99 & $14 \%$ & 2077 & 38,1 & $1,8 \%$ \\
\hline 90 & 1.5 & 8,92 & 1,20 & $13 \%$ & 2066 & 34,6 & $1,7 \%$ \\
\hline 0 & 11.5 & 4,35 & 0,90 & $21 \%$ & 2158 & 82,7 & $3,8 \%$ \\
\hline 15 & 11.5 & 4,66 & 0,94 & $20 \%$ & 2059 & 51,3 & $2,5 \%$ \\
\hline 30 & 11.5 & 4,95 & 1,01 & $20 \%$ & 2092 & 27,9 & $1,3 \%$ \\
\hline 60 & 11.5 & 7,13 & 0,90 & $13 \%$ & 2102 & 35,2 & $1,7 \%$ \\
\hline 90 & 11.5 & 9,34 & 2,19 & $23 \%$ & 2086 & 51,0 & $2,4 \%$ \\
\hline 0 & 21.5 & 5,30 & 0,83 & $16 \%$ & 2076 & 56,2 & $2,7 \%$ \\
\hline 15 & 21.5 & 4,76 & 0,40 & $8 \%$ & 2044 & 23,0 & $1,1 \%$ \\
\hline 30 & 21.5 & 6,32 & 1,13 & $18 \%$ & 2099 & 29,0 & $1,4 \%$ \\
\hline 60 & 21.5 & 8,38 & 1,51 & $18 \%$ & 2027 & 34,6 & $1,7 \%$ \\
\hline 90 & 21.5 & 12,43 & 2,74 & $22 \%$ & 2044 & 37,8 & $1,8 \%$ \\
\hline
\end{tabular}

Due to the large occurring deformations all stresses were calculated using an updated cross section. The horizontal deformation is used to update the cross section $A_{\text {new }}$ at every measurement point, by using Eq. (2) [42]:

$A_{\text {new }}=A_{0} \cdot \frac{2}{\pi}\left\{\cos ^{-1}\left(\frac{\Delta h}{D}\right)-\left(\frac{\Delta h}{D}\right) \sqrt{1-\left(\frac{\Delta h}{D}\right)^{2}}\right\}$

where $A_{O}$ is the initial sample area, $D$ is the sample diameter, and $\Delta h$ the horizontal shear displacement.

Typical shear stress-displacement data are shown in Fig. 12 for a concrete age of $30 \mathrm{~min}$. Similar to the compression tests, using the 5 experiments for each age and normal load combination, an average shear stress-displacement relation can be determined as indicated by the black solid line. Fig. 13 gives an overview of the average stressstrain relation for each concrete age. The shear strength $\tau_{y}$ is defined for each test as the maximum occurring stress after area correction, and is summarized in Table 3 along with each sample's density.

The average shear strength at $t=0$ is equal to $3.11 \mathrm{kPa}$ and develops in a linear fashion towards $8.92 \mathrm{kPa}$ at $t=90 \mathrm{~min}$, as depicted in Fig. 14. This rate of strength development found in the DST is equal to the results of the UUCT test as shown in Fig. 15, where the normalized compressive strength is plotted versus the normalized shear strength. The linear fit makes a $45^{\circ}$ angle with the abscissa and ordinate, which

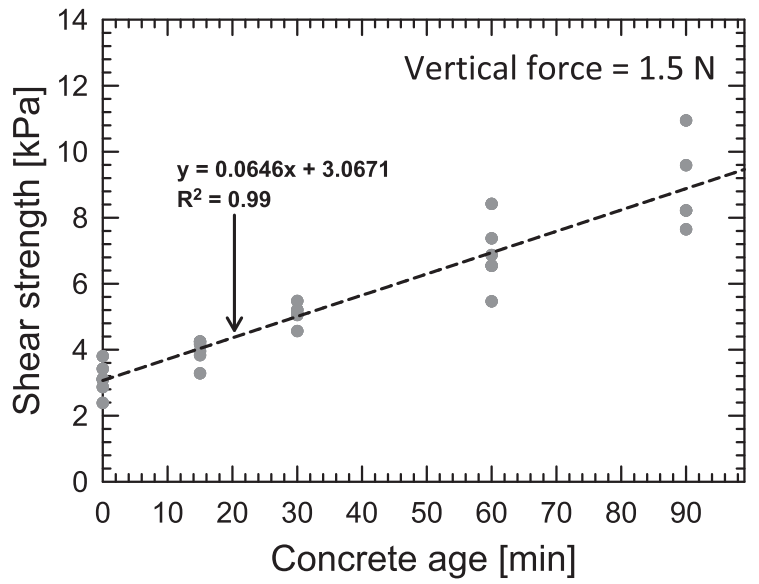

Fig. 14. Shear strength development up to 90 min derived from the direct shear tests with normal load $1.5 \mathrm{~N}$. The grey marks indicate the individual test results, the dashed black line represents a linear fit with $\mathrm{R}^{2}=0.99$, based on the average test results. indicates an equal rate of development.

As expected according to the Mohr-Coulomb theory, the addition of a vertical normal load increases the shear strength. Fig. 16 shows the relationship between the maximum shear stresses and the corresponding normal stresses for concrete age $t=0$ to $90 \mathrm{~min}$.

\subsubsection{Derivation of model parameters}

A linear development of strength and stiffness in time was derived for the first 90 mins of concrete age. This linear trend falls in line with common considerations of fresh concrete prior to setting [28,43].

Using the results of the direct shear tests, the Mohr-Coulomb parameters can be defined as a function of age for this material. The cohesion $\mathrm{C}$ corresponds to the intercept of the dashed lines with the ordinate in Fig. 16 and the slope is the angle of internal friction $\varphi$. The cohesion is equal to $3.05 \mathrm{kPa}$ at $t=0 \mathrm{~min}$ and increases in a linear fashion to $8.27 \mathrm{kPa}$ at $t=90 \mathrm{~min}$, given by the function:

$C(t)=0.058 \cdot t+3.05$

It should be noted that the experimental results inhibit considerable scatter, which may be attributed to the sensitivity of the 3DCP setup. Even though this still results in a clear linear time-dependency for the cohesion, such an obvious proportion between age and the angle of internal friction could not be established. Fig. 17 shows that the average values of $\varphi$ for each age all lie within one standard deviation of each other. Therefore, a constant value of angle of internal friction $\varphi=20^{\circ}$ was adopted. The constant nature of this value falls in line with experimental findings on fresh concrete [25] and is a conservative choice.

Substituting (3) in (1) results in the Mohr-Coulomb criterion as a function of concrete age:

$\tau(t)=C(t)+\sigma_{n} \cdot \tan (\varphi(t))=(0.058 \cdot t+3.05)+\sigma_{n} \cdot \tan \left(20^{\circ}\right)$

Using the results of the compression tests, the stiffness and deformation behaviour in time is derived. The Young's modulus as a function of concrete age was determined at $5 \%$ strain and equals:

$E(t)=0.0012 \cdot t+0.078$

The Poisson's ratio was derived from the lateral deformations in the compression tests, again at 5\% strain. This ratio appears to be approximately constant in the first $90 \mathrm{~min}$ and is equal to $v=0.3$.

Concrete, like soil and rock, shows a non-associated, dilatant plastic behaviour. As dilation effects largely occur after the peak load has been reached (and the object is considered failed), they have not been

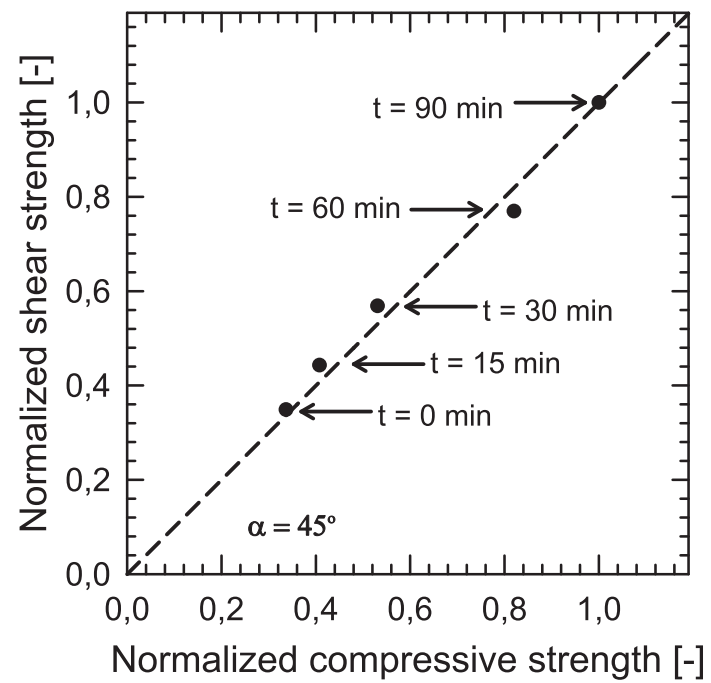

Fig. 15. Comparison between the compressive strength and shear strength up to $90 \mathrm{~min}$. All values are normalized to their maximum average value at $t=90 \mathrm{~min}$. The dashed line represents the linear fit and makes a $45^{\circ}$ angle with the axes, indicating an equal rate of development. 

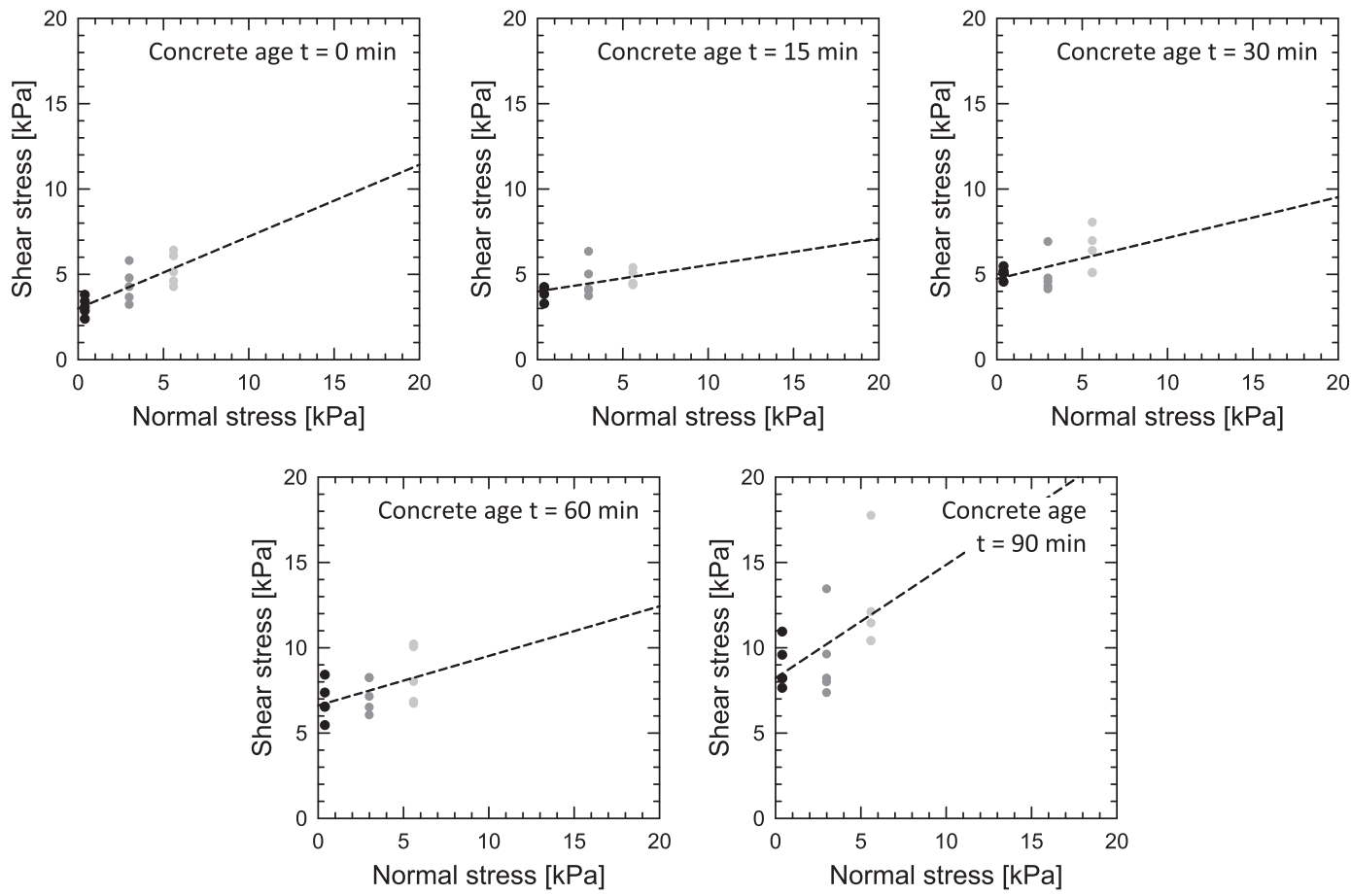

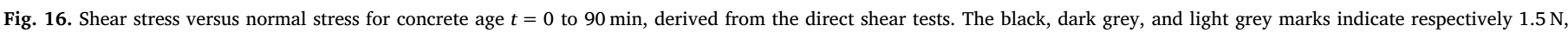
$11.5 \mathrm{~N}$, and $21.5 \mathrm{~N}$ vertical force applied. The dashed line represents a linear fit through the average values.

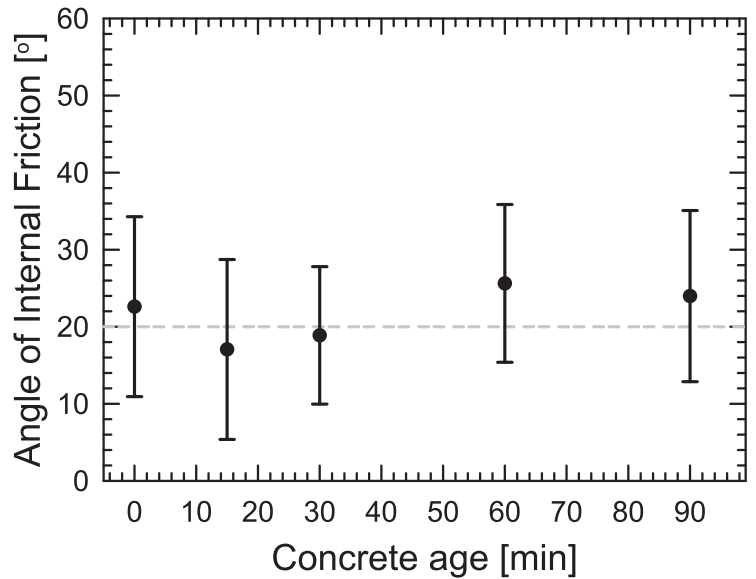

Fig. 17. Angle of Internal Friction for concrete age $t=0$ to $90 \mathrm{~min}$. The black marks represent the average values, and the standard deviation is indicated by error bars. They dashed grey line indicates a constant value equal to $\varphi=20^{\circ}$.

measured in this study. For the numerical analysis, a dilatancy angle of $\psi=13^{\circ}$ was assumed, equal to a typical value for hardened concrete [44]. Similar to the angle of internal friction, it is independent of fresh concrete age.

Five essential material parameters have now been defined to numerically model printed concrete of age $t=0$ to 90 min namely the Young's modulus $E(t)$, Poisson's ratio $v$, the Mohr-Coulomb parameters cohesion $C(t)$ and angle of internal friction $\varphi$, and the dilatancy angle $\psi$. Two parameters are linearly age dependent, the other three are constant within the considered time frame. They are used as input for numerical modelling as discussed in the next section.

\section{Numerical model}

Finite Element Method (FEM) analyses were carried out in two steps using the commercially available Abaqus FE-code. The first step

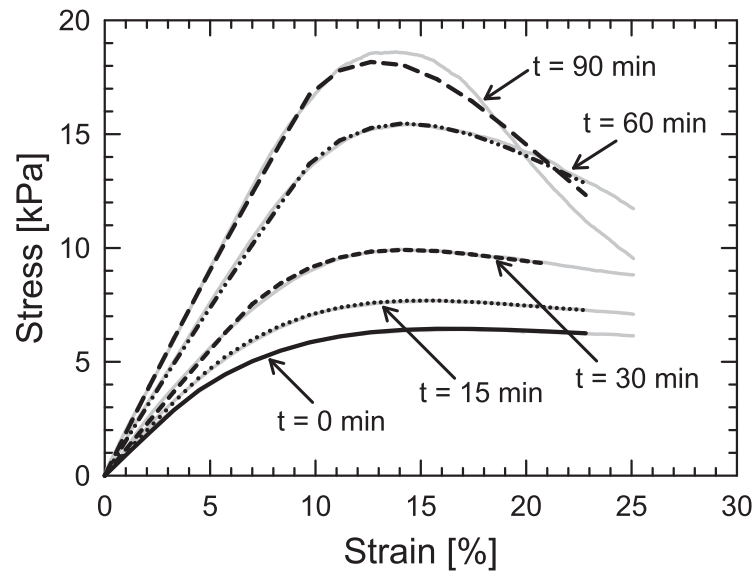

Fig. 18. Comparison between the experimental (grey) and numerical (black) stress-strain results of the compressions test, for concrete age $t=0$ to $90 \mathrm{~min}$.

concerns validation of the Mohr-Coulomb material model in Abaqus by simulating the compression and shear tests from the experimental program as described in Section 3. In the second step this material model is used to simulate the structural behaviour during an actual printing process and study the failure-deformation mode.

\subsection{Compression test}

A numerical model of the compression test was used to analyse the strength and deformation characteristics of the fresh concrete, based on the experimental results. An axisymmetric model was adopted, given the cylindrical shape of the specimens. The dimensions were taken equal to those of the experiments, i.e. $r=35 \mathrm{~mm}$ and $h=140 \mathrm{~mm}$. A regular mesh of axisymmetric linear 4-node continuum elements was used, which consisted of $10 * 40$ elements in the radial $r$, and axial $Z$, directions respectively.

Due to the Teflon on Teflon contact used in the experiments, the 


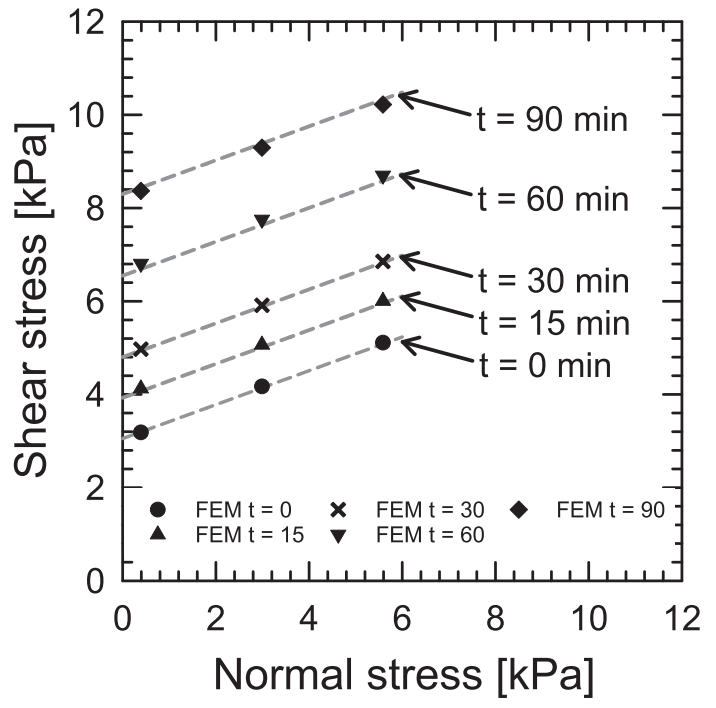

Fig. 19. Comparison between experimental and numerical results of the shear tests. The dashed lines represent the Mohr-Coulomb failure criterion for each concrete age, and the markers indicate the failure stresses derived from the FEM analyses.

boundary conditions at the specimen edges are taken as free in radial $r$ direction. A deformation of $35 \mathrm{~mm}$ in negative $z$ direction was imposed on the top edge of the cylinder, which corresponds to $25 \%$ vertical strain. The bottom edge was simply supported in $z$ direction.

The age dependent material parameters as discussed in Section 3.3.3. were used. The analysis was performed for each age as tested in the experimental program. The resulting stress-strain diagrams in loading direction were compared to the experimental results, see Fig. 18. The numerical results (in black) are in good agreement with the experimental findings (in grey). As such, the numerical model is deemed suitable to predict the stiffness and deformation behaviour of fresh concrete.

\subsection{Shear test}

A numerical model of the direct shear test was used to evaluate the Mohr-Coulomb parameters as derived from the experimental results. A cylindrical 3D model was used, with dimensions equal to those of the experiments, i.e. $d=70$ and $h=40$. Because of symmetry only half of the specimen was modelled. The aluminum plates of the shear box apparatus containing the specimens were modelled as rigid surfaces, including the small gap of $0.5 \mathrm{~mm}$ between the two plates as used in the experimental setup. The interface between concrete and the box walls was modelled using Tie-constraints. A regular mesh of linear 8-node continuum elements was applied. The Mohr-Coulomb failure criterion was used, and the material behaviour was assumed to be linear elastic up until the failure stress as found in the experimental program was reached.

The analysis was carried out in two steps. In the first step, the selfweight of the sample was activated and, when applicable, a normal load is applied on top of the specimen. In the second step, a horizontal displacement of $25 \mathrm{~mm}$ was imposed onto the top plate. The analysis was carried out for three external normal loads of 0,10 and $20 \mathrm{~N}$, which were applied as an evenly distributed pressure load. These three analyses were repeated for each concrete age as tested in the experimental program. The failure stress was then recorded and compared with the experimental results. The Mohr-Coulomb criterion as a function of time (Eq. 4) was plotted for the five different concrete ages as used in the experimental program, represented by the dashed grey lines in Fig. 19. The failure stress from the FEM analyses for three normal loads is indicated by the markers. The numerical results are in accordance with the experimental findings. Considering the agreement between experimental results on the one hand, and the material model and failure criterion on the other, the numerical method was considered suitable to analyse the printing process.

\subsection{Print process}

The printing process was modelled for a layered cylinder with a heart line radius of $250 \mathrm{~mm}$, a thickness of $40 \mathrm{~mm}$, and a layer height of $10 \mathrm{~mm}$. These layer dimensions follow from the nozzle used in the 3DCP setup. By applying the model change option in ABAQUS, the layers were added stepwise on top of each other continuously during the analysis, until failure occurs. The time interval $t_{\text {interval }}$ between these layers was based on the chosen printing speed of $v_{\text {print }}=5000 \mathrm{~mm} / \mathrm{min}$, divided by the circumference of each layer: $t_{\text {interval }}=\pi d$ / $v_{\text {print }}=0.31 \mathrm{~min}$. The strength and stiffness properties of each layer are then calculated during the analysis based on their age in the printing process: e.g. after 10 layers, the initial layer will be $3.10 \mathrm{~min}$ old and use the corresponding properties of that age, while the fifth layer of the model will have the properties of $1.55 \mathrm{~min}$ old, and so on.

Axisymmetric linear 4-node continuum elements were applied. Each layer consists of 40 by 10 elements in width and height direction, respectively. The bottom layer is fixed, due to the high friction on the print bed in practice. Each layer has a gravity loading pointing downwards based on the average density of $2070 \mathrm{~kg} / \mathrm{m}^{3}$ measured in the shear and compression tests. A Geometrical Non Linear analysis was performed to incorporate the influence of large deformations during the printing process. Default direct solver settings were used, with the exception of an unsymmetrical matrix storage due to the non-associated material behaviour. No initial imperfections were defined, as the
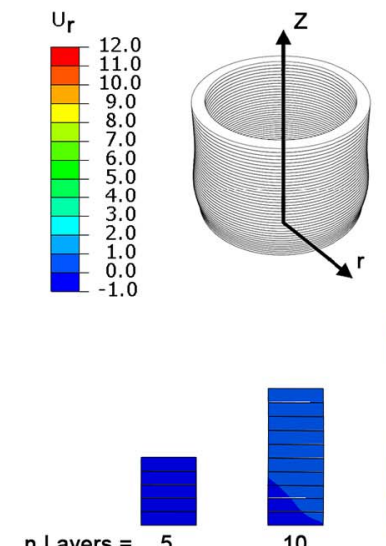

$\mathrm{n}$ Layers $=5$

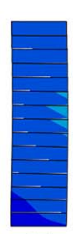

15
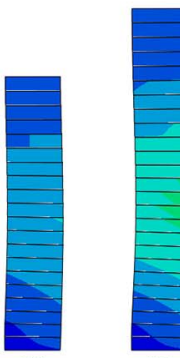

20

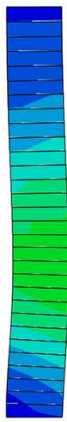

30

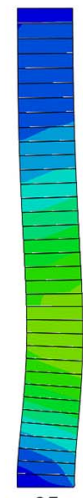

35

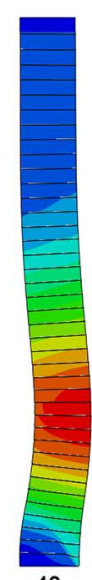

40

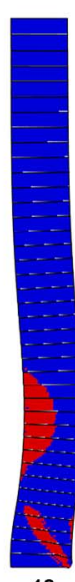

40
Fig. 20. Numerical results of an axisymmetric modelled cylinder, depicted for 5 to 40 layers, using the lower bound material properties. The plotted colors represent the radial deformations. On the right, the red color indicates where the yield stress is reached and plastic deformation occurs. (For interpretation of the references to color in this figure legend, the reader is referred to the web version of this article.) 

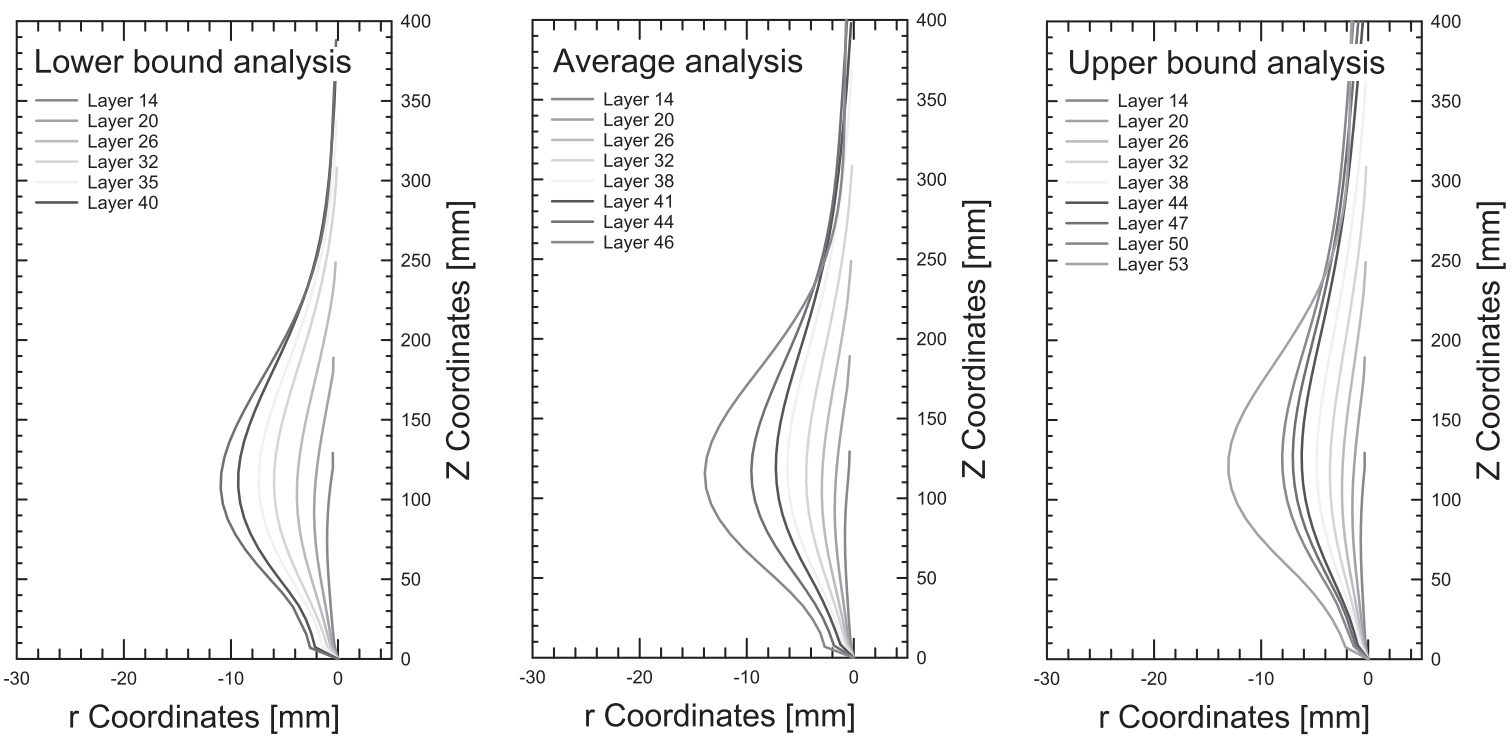

Fig. 21. FEM results showing deformed shape of cylinders for the lower bound (left), average (center) and upper bound (right) case.

Table 4

Summary of numerical results for the lower bound, average, and upper bound analyses.

\begin{tabular}{llll}
\hline Analysis & $\begin{array}{l}\text { Number of } \\
\text { layers }\end{array}$ & $\begin{array}{l}\text { Max. radial } \\
\text { deformation before } \\
\text { failure }[\mathrm{mm}]\end{array}$ & $\begin{array}{l}\text { Z position of max. radial } \\
\text { deformation }[\mathrm{mm}]\end{array}$ \\
\hline Lower bound & 40 & 11,0 & 106,7 \\
$\begin{array}{l}\text { Average } \\
\text { Upper bound }\end{array}$ & 56 & 13,89 & 115,8 \\
\hline
\end{tabular}

failure-deformation mode can be initiated by restrained lateral deformations (expansion) close to the support.

Three different cases were analysed to study the impact of the relatively large scatter in material properties during the printing process. The average values derived from the experiments were used, along with an upper and lower bound of strength and stiffness parameters. The relative standard deviation of the experimental strength and stiffness values is approximately $17.5 \%$ of their corresponding average values. This value was therefore used as both reduction and increase of the average (AVG) values, i.e. $0.825 * \mathrm{AVG}$ and $1.175 * \mathrm{AVG}$, to obtain a lower and upper bound estimation of the failure-deformation mode.

Fig. 20 shows the deformation shape and horizontal deformations in the layers at different stages, i.e. 5 to 40 layers, for the analyses with lower bound material properties. It is observed that in all three analyses the failure-deformation mode is a combination of instability (cylindrical buckling) and material yielding. Generally, cylindrical buckling is initiated first by restrained radial deformations due to the support conditions. The radial buckling deformation increases as layers are added to the structure. Simultaneously, the stresses due to the self-weight of the layers increase and ultimately reach the limit as defined by the Mohr-Coulomb criterion in the lower parts of the cylinder. At this point, the material will start yielding and significantly deform. The regions in a plastic state just before failure are indicated by the red color in Fig. 20. These plastic deformations, along with the continuous increase of vertical loading, lead to a second order bending moment which grows until global failure is reached.

In Fig. 21 the deformed cylinders are plotted in different stages for all three analyses, and the results are summarized in Table 4. The $17.5 \%$ increase or decrease in material properties significantly influence the moment of failure. The cylinder with AVG values failed after 46 layers, while the lower bound values led to failure at 40 layers, and the higher bound at 53 layers. The type of failure however, remains identical. No clear relation for the maximum radial deformation can be derived, which can be explained by two counteracting phenomena. A reduction of stiffness leads to higher deformations, while simultaneously, due to the reduction of strength, the cylinder fails at a lower number of layers. As such, the overall loading and corresponding deformation is less. The vertical position where the radial deformation is at a maximum is approximately equal for all three analyses.

\section{Validation}

The cylinder of the numerical program was printed using the same settings, i.e. layer dimensions of 40 by $10 \mathrm{~mm}$, a radius of $250 \mathrm{~mm}$, and printing speed of $5000 \mathrm{~mm} / \mathrm{min}$. To compare the failure-deformation mode of the numerical analyses with the printed cylinders, a noncontacting optic measurement system was used (Fig. 22). During the printing process, small circular markers were placed onto the fresh material on two sides of the cylinder. The object was exposed to red colored LED light, to increase the contrast between the markers and the fresh concrete. Two Basler Ace Ethernet camera's with an Edmund Optics fixed focal length lens were placed on both sides of the cylinder, and continuously took high resolution photographs of the current state

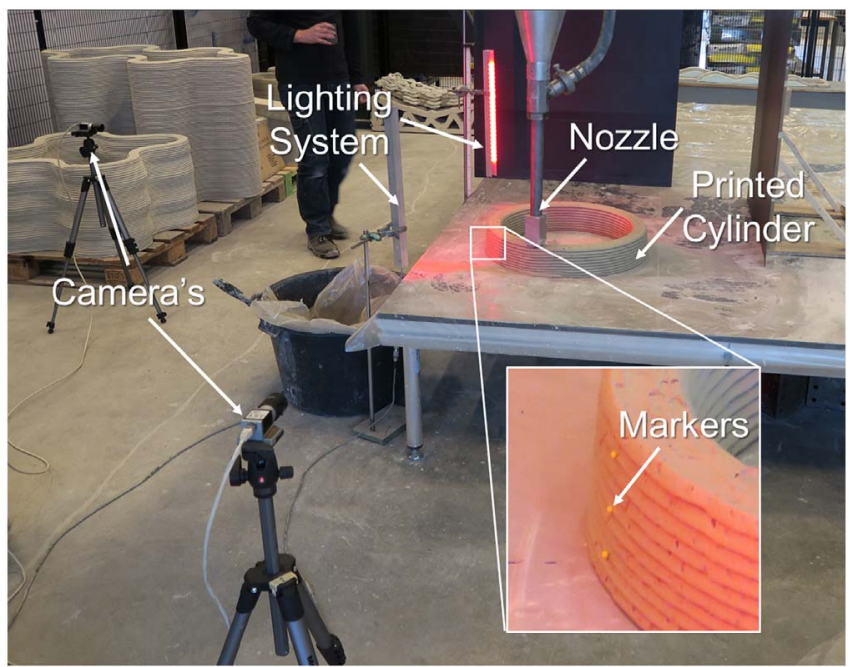

Fig. 22. Experimental setup to monitor deformations and failure during the printing process. 

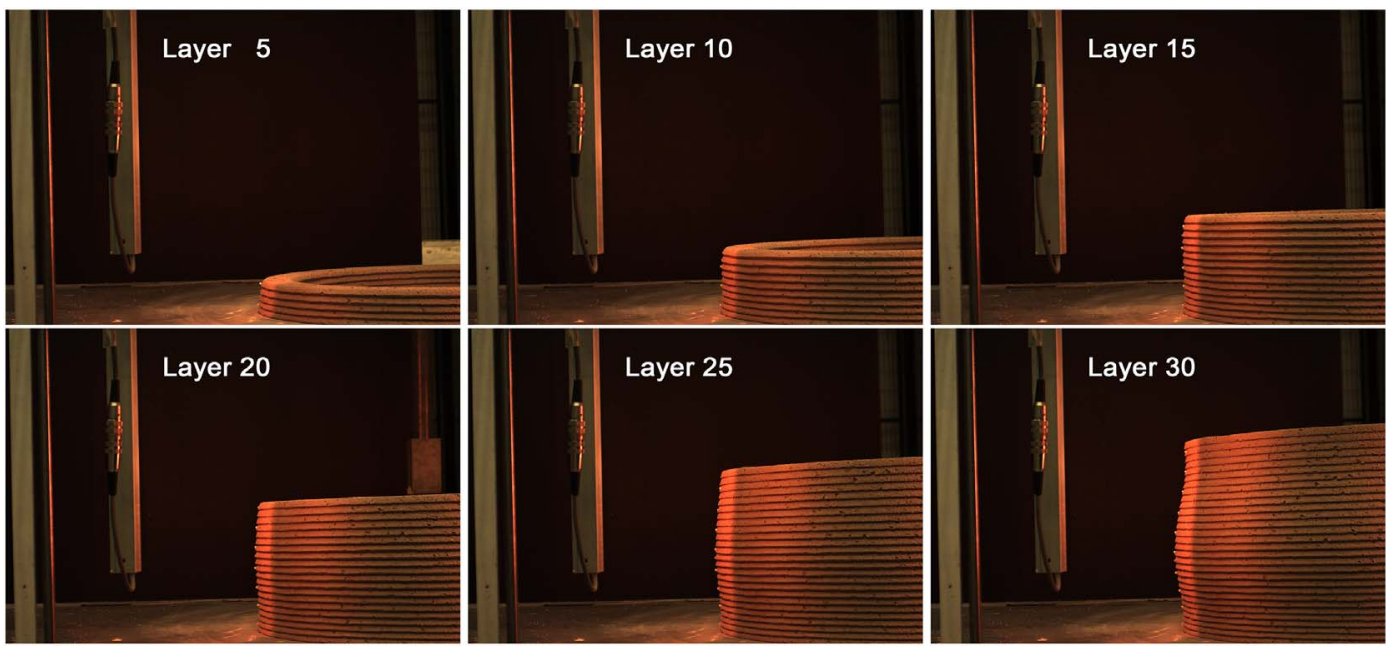

Fig. 23. Deformed shape of a cylinder during the printing process, visualized at 5 to 30 layers.
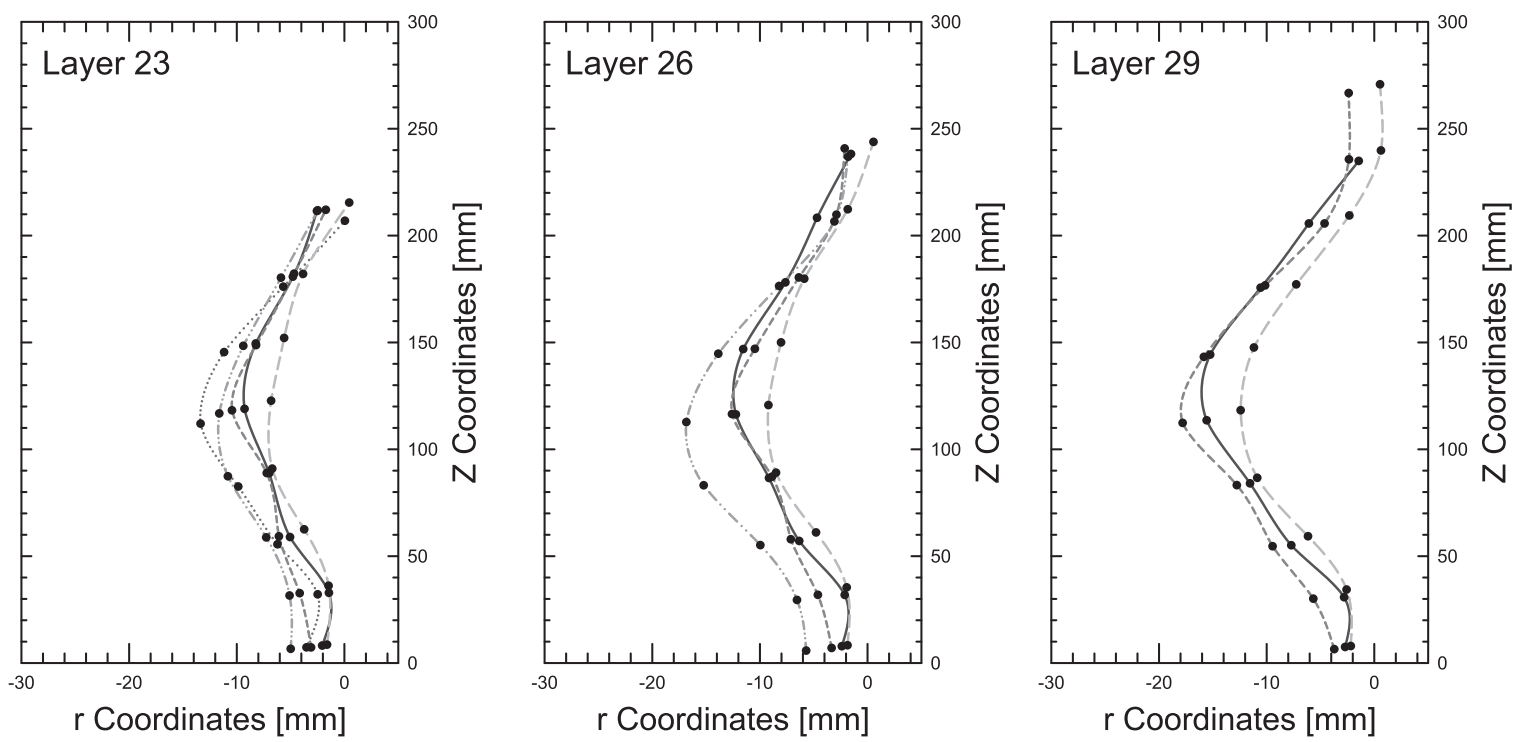

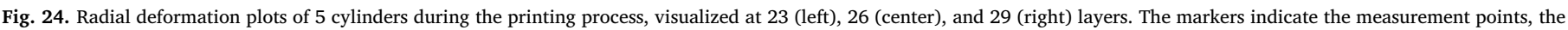
continuous lines are a smooth fit through these points.

of the printed object. These photos were then analysed real time in NI Vision software, where the circular trackers were used to compute the deformation during the printing process. This print experiment was carried out 5 times.

Typical deformation results are visualized in Fig. 23, for a printed cylinder after 5, 10, 15, 20, 25, and 30 layers. A cylindrical buckling deformation is observed for each printed cylinder, similar to the results of the FEM analyses. The five printed cylinders collapsed after 30, 25, 31,27 , and 31 layers respectively, resulting in an average cylinder height of 29 layers.

Using the Vision software, deformation plots can be generated similar to the numerical results of the previous section. Fig. 24 depicts the deformed shape of all 5 cylinders after 23, 26, and 29 layers. The markers indicate the measured values, while the continuous lines are a fit-line through these points that represent the geometry of the cylinder. Note that the step size of three layers follows from the spacing of markers in the cylinder, i.e. one in every three layers.

When comparing the numerical results to the printing experiments, it can be concluded that the FEM model qualitatively predicts the failure-deformation mode during the printing process. In practice however, the cylinders collapse in an earlier stage and deform more at a lower load (i.e. fewer layers). The experimental results are summarized in Table 5. The average number of 29 layers reached in the experiments deviates $27.5 \%$ from the 40 layers according to the lower bound numerical analysis. The average experimental radial deformation just before failure, here measured at 29 layers, is equal to $15.3 \mathrm{~mm}$, which corresponds to $139 \%$ of the lower bound numerical analysis. The

Table 5

Summary of failure-deformation results of five printed cylinders, with average values $\mu$ standard deviation $\sigma$, relative standard deviation RSD.

\begin{tabular}{|c|c|c|c|c|c|c|c|}
\hline & \multirow[t]{2}{*}{$\begin{array}{l}\text { Number } \\
\text { of layers }\end{array}$} & \multicolumn{3}{|c|}{ Max. radial deformation [mm] } & \multicolumn{3}{|c|}{$\begin{array}{l}\mathrm{Z} \text { position of max. radial } \\
\text { deformation }[\mathrm{mm}]\end{array}$} \\
\hline & & Layer 23 & Layer 26 & Layer 29 & $\begin{array}{l}\text { Layer } \\
23\end{array}$ & $\begin{array}{l}\text { Layer } \\
26\end{array}$ & $\begin{array}{l}\text { Layer } \\
29\end{array}$ \\
\hline$\mu$ & 29 & 10,3 & 12,7 & 15,3 & 114,7 & 116,5 & 114,7 \\
\hline$\sigma$ & 2,4 & 2,2 & 2,7 & 2,2 & 4,5 & 2,8 & 2,6 \\
\hline RSD & $8 \%$ & $21 \%$ & $21 \%$ & $14 \%$ & $4 \%$ & $2 \%$ & $2 \%$ \\
\hline
\end{tabular}


location (vertical height) at which the maximum radial buckling deformation is at a maximum, is approximately equal for both the experimental and numerical results, as all results are within a range of $10 \mathrm{~mm}$, i.e. one layer, of each other.

Two main reasons are distinguished for the discrepancy between numerical and experimental results. Firstly, axially loaded shells are sensitive to geometrical imperfections that cause eccentricity in the application of vertical loading, and to material imperfections (non-homogeneity). The critical buckling load of a shell with imperfections can be several times lower than according to classical theory [45]. As imperfections have not yet been incorporated into the numerical model, it underestimates deformations and overestimates the moment of failure.

Secondly, the properties as derived in the experiments are for a material that has been extracted from the 3D printer, and compacted afterwards to realize a homogeneous sample. This, however, significantly results in improved material properties (increased strength and stiffness, decreased compressibility) in comparison to the actual printed concrete that is not compacted in the process.

\section{Conclusions}

In this study, a numerical model was developed to analyse the mechanical behaviour of early age 3D printed concrete, in the range of 0 to $90 \mathrm{~min}$ after material deposition. An experimental program, consisting of unconfined uniaxial compression tests (UUCT) and direct shear tests (DST), was set-up and performed to obtain the required material properties. Subsequently, the model was validated by comparison to printing experiments. A number of novel insights and conclusions are summarized below:

The numerical model is deemed suitable to analyse the structural behaviour of a concrete object during 3D printing, and qualitatively predict the corresponding failure-deformation mode. Quantitatively, however, the model overestimates the strength and stability of the object. This is likely due to overestimation of the material properties from testing because of compaction of the specimens, and due to disregarding the influence of geometrical and material imperfections induced by the printing process.

The Mohr-Coulomb theory as applied in the numerical model, i.e. extended with time dependent development of material properties, may be considered as a satisfactory failure criterion for fresh 3D printed concrete. In this study, the cohesion was found to be a linear function of time, and the angle of internal friction independent of age, within the time frame of a typical printing process.

Finally, it may be concluded that geotechnical (soil) tests are suitable to assess the properties of early age printed concrete. In this study, the Young's modulus, compressive strength and shear strength were found to be a linear function of time, and develop proportionally with fresh concrete age. The authors recommend to develop and apply tests which can assess the properties of printed concrete without compaction.

\section{Acknowledgements}

The support of the staff of the Structures Laboratory Eindhoven is greatly acknowledged. The assistance in the 3DCP research of Master track students Structural Design at the TU/e Department of the Built Environment is highly valued. For this paper, the authors appreciate the work of T. Krijntjes, J. Hermus and C. Maas in particular, on whose MSc project the material presented is partially based.

The TU/e research program on 3D Concrete Printing is co-funded by a partner group of enterprises and associations, that on the date of writing consisted of (alphabetical order) Ballast Nedam, BAM Infraconsult bv, Bekaert, Concrete Valley, CRH, Cybe, Saint-Gobain Weber Beamix, SGS Intron, SKKB, Van Wijnen, Verhoeven Timmerfabriek, and Witteveen + Bos. Their support is gratefully acknowledged.

\section{References}

[1] S. Lim, R.A. Busswel, T.T. Le, S.A. Austin, A.G.F. Gibb, T. Thorpe, Developments in construction-scale additive manufacturing processes, Autom. Constr. 21 (2012) $262-268$.

[2] B. Khoshnevis, D. Hwang, K.T. Yao, Z. Yeh, Mega-scale fabrication by contour crafting, Int. J. Ind. Syst. Eng. 1 (3) (2006) 301-320.

[3] N. Labonette, A. Rønnquist, B. Manum, P. Rüther, Additive construction: state-ofthe-art, challenges and opportunities, Autom. Constr. 72 (3) (2016) 347-366.

[4] I. Perkins, M. Skitmore, Three-dimensional printing in the construction: a review, Int. J. Confl. Manag. 15 (1) (2015) 1-9.

[5] F.P. Bos, R.J.M. Wolfs, Z.Y. Ahmed, T.A.M. Salet, Additive manufacturing of concrete in construction: potentials and challenges, Virtual Phys. Prototyp. 11 (3) (2016) 209-225.

[6] B. Sevenson, Shanghai-based WinSun 3D Prints 6-Story Apartment Building and an Incredible Home, https://3dprint.com/38144/3d-printed-apartment-building/, (2015), Accessed date: May 2017(Online).

[7] E. Krassenstein, EXCLUSIVE: Lewis Grand Hotel Erects World's First 3D Printed Hotel, Plans to Print Thousands of Homes in the Philippines Next, https://3dprint. com/94558/3d-printed-hotel-lewis-grand/, (2015) , Accessed date: May 2017(Online).

[8] B.B. Millsaps, Heijmans \& CyBe Construction Showing Off Success with 3D Printed Cement Frameworks, https://3dprint.com/138682/heijm-cybe-3d-printedcement/, (2015) , Accessed date: May 2017(Online).

[9] C. Scott, Apis Cor 3D Prints a House in 24 Hours and Creates a Technological Showcase, https://3dprint.com/166389/apis-cor-3d-printed-house-russia/, (2017) , Accessed date: May 2017(Online).

[10] N. Roussel, F. Cussingh, Distinct-layer casting of SCC: the mechanical consequences of thixotropy, Cem. Concr. Res. 38 (2008) 624-632.

[11] T.T. Le, S.A. Austin, S. Lim, R.A. Buswell, R. Law, A.G.F. Gibb, T. Thorpe, Hardened properties of high-performance printing concrete, Cem. Concr. Res. 42 (2012) 558-566.

[12] R. Duballet, C. Gosselin, P. Roux, Additive manufacturing, multi-objective optimization of graded polystyrene aggregate concrete structures, Modelling Behaviour, 2015, pp. 225-235.

[13] T.A.M. Salet, F.P. Bos, R.J.M. Wolfs, Z.Y. Ahmed, 3D Concrete Printing - A Structural Engineering Perspective, Proc. of FIB Symp. 2017 Maastricht, (2017).

[14] T.T. Le, S.A. Austin, S. Lim, R.A. Buswell, A.G.F. Gib, T. Thorpe, Mix design and fresh properties for high-performance printing concrete, Mater. Struct. 45 (2011) 1221-1232.

[15] A. Kazemian, X. Yuan, E. Cochran, B. Khoshnevis, Cementitious materials for construction-scale 3D printing: laboratory testing of fresh printing mixture, Constr. Build. Mater. 145 (2017) 639-647.

[16] A.J. Dunbar, E.R. Denlinger, M.F. Gouge, P. Michaleris, Experimental validation of finite element modeling for laser powderbed fusion deformation, Addit. Manuf. 12 ( (2016) 108-120.

[17] T. Di Carlo, Experimental and Numerical Techniques to Characterize Structural Properties of Fresh Concrete Relevant to Contour Crafting, Dissertation (Partial Fulfillment), University of Southern California, (2012).

[18] A. Perrot, D. Rangeard, A. Pierre, Structural built-up of cement-based materials used for 3D printing extrusion techniques, Mater. Struct. 49 (4) (2015) 1213-1220.

[19] T. Wangler, E. Lloret, L. Reiter, N. Hack, F. Gramazio, M. Kohler, M. Bernhard, B. Dillenburger, J. Buchli, N. Roussel, R. Flatt, Digital concrete: opportunities and challenges, RILEM Tech. Lett. 1 (2016) 67-75.

[20] E. Lloret, A.R. Shahab, M. Linus, R.J. Flatt, F. Gramazio, M. Kohler, S. Langenberg, Complex concrete structures - Merging existing casting techniques with digital fabrication, Comput. Aided Des. 60 (2015) 40-49.

[21] T. Voigt, J.J. Mbele, K. Wang, S.P. Shah, Using fly ash, clay, and fibers for simultaneous improvement of concrete green strength and consolidatability for slipform pavement, J. Mater. Civ. Eng. 22 (2) (2010) 196-206.

[22] H.J. Wierig, Einige Beziehungen zwischen den Eigenschaften von "grünen" und "jungen" Betonen und denen des Festbetons, Betontechnische Berichte, Betonverlag Düsseldorf (1971) 151-172.

[23] R. Bornemann, M. Schmidt, Fundamentals and strategies for improvement of noslump concretes, Part I, Betonw. Fert. Tech. 69 (8) (2005) 44-51.

[24] G. Hüsken, H.J.H. Brouwers, On the early-age behaviour of zero-slump concrete, Cem. Concr. Res. 42 (2012) 501-510.

[25] A. Alexandridis, N.J. Gardner, Mechanical behaviour of fresh concrete, Cem. Concr. Res. 11 (1981) 323-339.

[26] G. Lu, K. Wang, Investigation into yield behavior of fresh cement paste: model and experiment, ACI Mater. J. 107 (1) (2010) 12-19.

[27] N. Roussel, A thixotropy model for fresh fluid concretes: theory, validation and applications, Cem. Concr. Res. 36 (2006) 1797-1806.

[28] N. Roussel, G. Ovarlez, S. Garrault, C. Brumaud, The origins of thixotropy of fresh cement pastes, Cem. Concr. Res. 42 (2012) 148-157.

[29] L.K. Mettler, F.K. Wittel, R.J. Flatt, H.J. Hermann, Evolution of strength and failure of SCC during early hydration, Cem. Concr. Res. 89 (2016) 288-296.

[30] R. Alfani, G.L. Guerrini, Rheological test methods for the characterization of extrudable cement-based materials - a review, Mater. Struct. 38 (2005) 239-247.

[31] R.H. Olsen, Lateral Pressure of Concrete on Formwork, Dissertation (Partial Fulfillment), Oklahoma State University, (1968).

[32] R. Hendrickx, K. van Balen, D. van Gemert, Yield Stress Measurement of Mortar Using Geotechnical Techniques, 3rd Int. RILEM Symp. on Rheology of Cement Suspensions such as Fresh Concrete, (2009), pp. 273-282.

[33] T. Voigt, T. Malonn, S.P. Shah, Green and early age compressive strength of 
extruded cement mortar monitored with compression tests, ultrasonic techniques, Cem. Concr. Res. 36 (2006) 858-867.

[34] Methods of Testing Cement - Part 3: Determination of Setting Times and Soundness, European Standard EN 196-3:2005, (2008).

[35] Standard Test Method for Unconfined Compressive Strength of Cohesive Soil, ASTM D2166, (2013).

[36] Standard Test Method for Direct Shear Test of Soils Under Consolidated Drained Conditions, ASTM D3080, (1998).

[37] J.J. Assaad, J. Harb, Y. Maalouf, Measurement of yield stress of cement pastes using the direct shear test, J. Non-Newtonian Fluid Mech. 214 (2014) 18-27.

[38] S.H. Liu, D. Sun, H. Matsuoka, On the interface friction in direct shear test, Comput. Geotech. 32 (2005) 317-325.

[39] L.S. Tang, H.T. Sang, J. Song, Z.G. Luo, Y.L. Sun, Mechanical model for failure modes of rock and soil under compression, Trans. Nonferrous Metals Soc. China 26
(2016) 2711-2723

[40] N.C. Consoli, M.A. Vendruscolo, A. Fonini, F.D. Rosa, Fiber reinforcement effects on sand considering a wide cementation range, Geotext. Geomembr. 27 (2009) 196-203.

[41] N. Hatibu, D.R.P. Hettiaratachi, The transaction from ductile flow to brittle failure in unsaturated soils, J. Agric. Eng. Res. 54 (1993) 319-328.

[42] J. Lai, Direct Shear Testing, Dep. of Construction Engineering Chaoyang University of Technology, 2004.

[43] J. Petit, K.H. Khayat, E. Wirquin, Coupled effect of time and temperature on variations of yield value of highly flowable mortar, Cem. Concr. Res. 36 (2006) $832-841$

[44] P.A. Vermeer, R. de Borst, Non-associated plasticity for soils, concrete and rock, Heron 29 (3) (1984) 1-64.

[45] M.L. Gambhir, Stability Analysis and Design of Structures, Springer, Berlin, 2004. 